\title{
Física e Literatura: uma revisão bibliográfica+*
}

\section{Luís Gomes de Limal}

Doutorando em Educação - modalidade Ensino de Ciências e Matemática Faculdade de Educação - USP

Elio Carlos Ricardo ${ }^{2}$

Faculdade de Educação - USP

São Paulo - SP

\section{Resumo}

Apresentamos uma revisão bibliográfica sobre pesquisas que focam as relações, dificuldades e propostas didáticas entre física e literatura. Pesquisamos, ao longo desse século, a produção acadêmica em revistas especializadas e atas de congressos em ensino de física, buscando nos resumos e títulos de trabalhos palavras-chave com os termos: ciência/física e literatura, leitura e ensino de ciências/física, divulgação/ficção científica e uso de analogias/metáforas no ensino de ciências/física. A escassez de trabalhos publicados na área nos levou a pesquisar revistas não especializadas em ensino de física, bem como a extrapolar o período de pesquisa. Buscamos compreender como a relação entre física e literatura vem sendo discutida pela área científica, identificando como o ensino de física pode se beneficiar dos recursos oferecidos pela literatura. De nossa revisão bibliográfica verificamos um grande potencial didático no uso da literatura e seus recursos como possível ferramenta didática ao ensino de física.

Palavras-chave: Física e literatura; Leitura; Analogias e metáforas; Ensino e aprendizagem.

\footnotetext{
${ }^{+}$Physics and Literature: a bibliographic review

* Recebido: janeiro de 2015.

Aceito: abril de 2015.

1 E-mail: luis.gomes.lima@usp.br

2 E-mail: elioricardo@usp.br
} 


\begin{abstract}
In this work, we are going to present a literature review of researches that focus on the relationships, difficulties and didactic proposals between Physics and Literature. We have researched on the scientific production of the academic community in specialized journals and congress minutes about Physics teaching, by seeking in abstracts and titles of academic works the following keywords: Science/Physics and Literature, reading and Science/Physics teaching, scientific dissemination/fiction, and use of analogies/metaphors in Science/Physics teaching. The scarcity of published studies led us to research in journals which are not specialized in Physics Education and to extrapolate the research period. We aim to understand how the relationship between Physics and Literature has been discussed by the scientific area, by identifying how the Physics Education can benefit from the resources offered by Literature. In this literature review, we have found a huge educational potential in the use of Literature and its resources as a possible didactic tool for Physics teaching.
\end{abstract}

Keywords: Physics and literature; Reading; Analogies and metaphors; Teaching and learning.

\title{
I. Introdução
}

O objetivo desse trabalho é investigar como as relações entre física e literatura, suas possibilidades de aprendizado e potenciais didáticos, aparecem nos estudos da área em ensino de física/ciências. Buscamos compreender como a literatura pode contribuir para um ensino de física que desenvolva maior aprendizagem nos alunos, bem como essa contribuição é percebida pelos estudiosos da área de ensino de física.

Um primeiro obstáculo, na compreensão da articulação entre física e literatura é em relação ao próprio termo literatura, de definição ampla e que necessita, preliminarmente, ser bem identificado para que possamos perceber seu potencial como possível ferramenta ao ensino de física. Assim, podemos perguntar quais seriam os elementos pertencentes, tanto à física quanto à literatura, que permitiriam um ensino articulado entre as duas disciplinas, aparentemente, tão distintas uma da outra?

Uma possível resposta a essa indagação pode ser especulada, inicialmente, mediante a definição do que é literatura. O termo literatura provem do latim littera que significa "letra". Entretanto, a literatura não se apresenta apenas no aspecto escrito. Não é apenas o fato de estar escrito que se considera um texto uma literatura, o que torna complexa a busca de uma definição para o termo, que pode, também, representar todo um corpo ou um conjunto escolhido de textos, 
tais como a literatura médica, a literatura inglesa, a literatura portuguesa, a literatura científica, filosófica, histórica, entre outras.

Existe, também, na literatura uma preocupação com a estética, a forma com que se escreve o texto pertencente a determinado conjunto literário. Na física, a estética também está presente no formalismo matemático, na forma de apresentação de um problema e na sua solução, e até mesmo nos nomes das teorias, portanto, há beleza envolvida, tanto em um texto bem escrito, quanto em um conceito físico bem elaborado.

Outra forma de se procurar entender a literatura é considerando-a como uma arte, como descrita por Coutinho (1978):

A Literatura, como toda arte, é uma transfiguração do real, é a realidade recriada através do espírito do artista e retransmitida através da língua para as formas, que são os gêneros, e com os quais ela toma corpo e nova realidade. Passa, então, a viver outra vida, autônoma, independente do autor e da experiência de realidade de onde proveio (COUTINHO, 1978, p. 9-10).

E, vale lembrar, também, da diferença entre literatura e estudo da literatura. De acordo com a Teoria da Literatura de Renè Wellek e Austin Warren (1962), existe uma distinção bem nítida entre literatura e estudo da literatura, constituindo-se em duas atividades bem distintas. Conforme Zilberman (2012): "Enquanto a literatura é criadora, uma arte; o estudo da literatura, embora não possa ser considerada precisamente como uma ciência, encontra-se como uma modalidade do conhecer ou do aprender" (ZILBERMAN, 2012, p. 22).

A literatura, portanto, pode ser considerada, de acordo com Wellek; Warren (1962) como arte e criação, que suscita experiência. Iremos nos reter, basicamente, no seu aspecto escrito, embora saibamos que extrapola a simples escrita, o que nos leva à importância de delimitar essa revisão bibliográfica sobre os estudos que se debruçaram sobre as relações entre a física e a literatura. Para tanto, consideraremos como literatura os trabalhos que envolvam a leitura, a escrita, a interpretação textual, o papel da divulgação/ficção científica, bem como o uso de analogias e metáforas no ensino de ciência/física, pois esses trabalhos, conforme a definição dada, aproximam-se do conceito e definição do termo literatura. Já o estudo da literatura, enquanto modalidade de conhecimento, não nos interessa para os fins que pretendemos, ou seja, o estudo da literatura fugiria ao objetivo dessa revisão bibliográfica sobre física e literatura.

Assim sendo, não se pretende explorar o estudo da literatura, mas somente esses elementos-chave, que possibilitam a articulação entre estas duas culturas: a física e a literatura. Importa que compreendamos que tanto para a física, quanto para a literatura, existe um momento de arte e de criação, onde tanto o cientista, quanto o literário, encontram-se em um mesmo "limbo" de imaginação. A diferença surge depois, principalmente, entre os métodos utilizados, tanto por um quanto por outro. Entretanto, um mesmo amálgama parece existir entre a física e a literatura. Sobre essa relação, Mecke (2004) afirma que: 
A literatura e a física habitam o mesmo ambiente cultural. Não só a física influencia a literatura como vice-versa. Não no sentido de uma causalidade direta, mas sim no de um quadro interpretativo comum, de uma língua comum, de imagens e metáforas comuns. Porque a fisica vive de metáforas poderosas (MECKE, 2004, p. 04).

Conforme o autor, existe um amálgama de criação, entre física e literatura, no que diz respeito a sua interpretação, por uma linguagem comum de criação e arte, interpretada pelas imagens e metáforas que pertencem tanto a uma cultura quanto à outra. Tendo em vista, que não se pode considerar como posto e, inteligível, por definição, o amálgama mencionado, iremos nos aprofundar nessa relação, a fim de que seja melhor compreendida.

Ainda, de acordo com Mecke (2004), os conceitos e metáforas físicos são encontrados em muitos discursos e textos, sendo que, em quase todos os livros, podemos encontrar expressões físicas, usadas dentro de uma determinada licença poética ou literária. O autor nos recorda de algumas, mais utilizadas:

\footnotetext{
Magnético - no sentido de uma atração sinistra e animal, frequentemente significando amor;

Salto quântico - no sentido de uma mudança superlativa;

Sinergia - no sentido de um misterioso fenômeno cooperativo (MECKE, 2004, p. 6).
}

Conceitos físicos, como os apontados acima, também estão presentes no jargão jornalístico. A importância dessa presença se dá pelo uso de metáforas, como ferramentas que possibilitam a transposição entre um conhecimento concreto e um conhecimento abstrato (KINOUCHI et al., 2012). Nesse trabalho é mostrada a presença de conceitos científicos no jargão jornalístico. Apesar dos autores demonstrarem que há aumento de certa divulgação científica, mediante o uso de termos científicos em situações descontextualizadas da ciência, não levam em conta os riscos da proliferação da semicultura ${ }^{3}$ inerente a essas abordagens. Aquém dessas considerações, trazem contribuições importantes ao levantarem a importância do uso de metáforas, como ferramentas que possibilitem a transposição didática entre um conhecimento concreto e um conhecimento abstrato.

Os autores inovam, ao usar o termo "metáforas" no sentido cognitivo e não no sentido comumente conhecido, o linguístico, respaldando-se na teoria cognitiva de Lakoff e Johnson (1980), na qual a essência da metáfora é "compreender e experimentar um tipo de coisa em termos de outra" (p. 47), um mapeamento entre um domínio fonte concreto e um domínio alvo abstrato (LAKOFF; JOHNSON, 1980; LAKOFF; NÚÑEZ, 2000). Assim, podemos relacionar a leitura de um texto literário como um domínio fonte concreto, enquanto esperamos que, dessa leitura, surjam elementos que levem a um domínio alvo abstrato, ou seja, um conceito físico.

\footnotetext{
${ }^{3}$ A semiformação ou semicultura é uma espécie de cultura criada e formatada pelos interesses da indústria cultural, portanto submetida aos interesses do mercado. A indústria cultural é para Adorno e Horkheimer (1985) a expressão máxima da deturpação do esclarecimento. Ela infiltra-se no projeto do esclarecimento como "idolatria daquilo que existe e do poder pelo qual a técnica é controlada” (HORKHEIMER E ADORNO, 1985, p. 16).
} 
Certamente, há uma "licença científica", utilizada pelos escritores para representarem suas ideias, contudo, existem, também, expressões físicas utilizadas conscientemente. Sobre essas expressões, Mecke (2004) nos recorda autores como Thomas Mann, Alfred Döblin e Umberto Eco, nos quais as expressões físicas tornam-se elemento de estilo:

\begin{abstract}
Uma função literária central da fórmula parece simbolizar a violência na edição que possuo de "Berlin Alexanderplatz" ilustrada por Georg Grosz. A fórmula torna-se metáfora para a violência, para o calculismo desumano, para a morte e para a fria mecânica - para o golpe de força. Tal encontra-se não só em Döblin como também em Thomas Pynchon, que, no seu romance "Gravity's Rainbow", descreve a queda de mísseis em Londres usando a fórmula de Poisson. Recorde-se também "O Pêndulo de Foucault", de Umberto Eco, onde a fórmula do pêndulo caracteriza o estrangulamento de um ser humano. Passo a citar: "O período de oscilação, $T$, é independente da massa do corpo suspenso (igualdade de todos os homens perante Deus)...". Também aqui a fórmula constitui uma referência irónica à marginalização do sujeito, reduzido à "massa inerte" suspensa (MECKE, 2004, p. 6-7).
\end{abstract}

Verifica-se que, nesse aspecto, a física e a literatura podem se traduzir, como indicado por Mecke (2004), em modelo e metáfora, respectivamente, levando-se em consideração que, tanto a física quanto a literatura, são formas de interpretar o mundo. O que guarda um potencial didático importante, pois é possível ao professor de física se utilizar dessa relação para mostrar o significado de um modelo científico. Na física há a interpretação abstrata e matemática dos modelos físicos, enquanto na literatura há a compreensão pela linguagem metafórica. Vale questionar se modelo e metáfora não seriam sinônimos, sendo a distinção dada pelas formas de interpretar os fenômenos, tanto um quanto o outro. O alerta de Mecke (2004) nos oferece uma resposta a essa indagação: "Na rotina do nosso quotidiano de físicos esquecemo-nos frequentemente de que são as metáforas, e não as fórmulas, que constituem a espinha dorsal do pensamento" (Idem, p.11).

Esse pequeno enxerto introdutório nos leva a percepção de que a literatura, compreendida em seu contexto mais amplo, pode servir como uma importante ferramenta didática para o ensino de física. Sobre esse contexto verificamos que também há a relação da física e da literatura com a imaginação, pois tanto o escritor, quanto o físico, necessitam de imaginação na elaboração de seus escritos, sejam literários ou científicos. As relações entre física e imaginação podem ser encontradas em alguns estudos, como os de Carvalho e Zanetic (2004; 2005); Gurgel e Pietrocola (2011); Paula e Borgens (2008) e Watanabe e Gurgel (2011).

A respeito dessas relações, verifica-se que a imaginação, quando trabalhada didaticamente por meio da literatura, pode ser considerada como a ponte que conecta uma aprendizagem não conceitual em conceitual, ou entre um conhecimento não científico em científico, podendo se constituir em boa estratégia de ensino. Gurgel e Pietrocola (2011), ao estudarem o processo da imaginação em um enfoque histórico-epistemológico, consideraram a imaginação como função do pensamento que busca apreender o real. Como referencial teórico, foi utilizado 
um resgate histórico da forma de pensar de Albert Einstein, no qual aparece a valorização da subjetividade do pensamento não conceitual, denominado como imaginação. Inclusive, os autores alertam para o fato de que o imaginário dos alunos é pouco explorado.

Como já discutido acima, a literatura também é representativa da arte. A física também possui aspectos, não só ligados à imaginação, mas, também, associados à arte, como defendido por Zanetic (2006). Ao estabelecer uma ponte entre essas duas culturas, o autor promove uma aproximação da física com diversas representações culturais, como a música, a história, a filosofia, a literatura, a divulgação científica, o teatro e as artes plásticas.

Ao que parece, a primeira tentativa de se aproximar a cultura científica e a cultura humanística foi elaborada pelo físico e romancista inglês Charles Percy Snow, que criou e cunhou a expressão "duas culturas" para retratar as diversidades entre cientistas e não cientistas. Conforme Snow (1995), os humanistas não conhecem conceitos básicos da ciência e os cientistas não tomam conhecimento das dimensões humanas que a ciência carrega. De acordo com o autor: "quando esses dois sentidos se desenvolvem separados, nenhuma sociedade é capaz de pensar com sabedoria" (SNOW, 1995, p.72).

A denúncia da dicotomia existente entre as duas culturas, a científica e a humanística, não é exclusividade da obra de Snow (1995). Segundo Rezende, Ostermann e Ferraz (2009), ao realizarem uma introspecção no estado da arte referente ao ensino de física nacional, nos anos de 2000 a 2007, apontam para estudos basicamente realizados sobre os aspectos cognitivos do ensino-aprendizagem, apoiados em apenas três eixos:

i. Desenvolvimento de experimentos para laboratórios didáticos;

ii. Propostas de metodologias;

iii. Estratégias de ensino e elaboração de recursos didáticos.

As autoras constatam, ainda, que há necessidade de pesquisas teóricas que levem à produção de conhecimento; a escassez de trabalhos teóricos pode, inclusive, dar a impressão que se faz sempre o mesmo no ensino de física nacional, não havendo, por exemplo, estudos articulados com outras áreas do saber. O que leva ao caráter urgente em se repensar os modelos investigativos sobre ensino de física, tanto na produção de conhecimento, quanto na investigação com áreas distintas da física. Em uma tabela, Rezende, Ostermann e Ferraz (2009) apresentam uma classificação dos trabalhos realizados, conforme diferentes temáticas, sendo que a temática classificada como arte, cultura e educação científica traz 0 (zero) pesquisas realizadas no período avaliado pelas autoras (REZENDE; OSTERMANN; FERRAZ, 2009, p.3).

No Brasil, ao que parece, a primeira obra que busca aproximar a física de uma dimensão cultural, é a tese de doutorado de Zanetic (1989). Nesse trabalho, o autor esclarece que o ensino de física, ou de qualquer outra área do conhecimento, ao ser ensinado por uma única perspectiva, como a do formalismo matemático, mediante a mera resolução de problemas, e o 
maçante repisar de repetições de exercícios, gera um risco grande de não estabelecer uma compreensão por parte dos alunos, sendo que o conhecimento físico deve ser considerado, também, como uma construção humana, como explica Zanetic (1989):

É claro que a aprendizagem da solução de problemas típicos, que envolve o domínio
de uma metodologia de trabalho, um formalismo matemático adequado, a utilização
correta de grandezas e unidades físicas, bem como a avaliação final do resultado
obtido, é parte fundamental da aquisição de conhecimentos físicos, é a parte que evi-
dencia o potencial do que foi aprendido na solução de problemas teóricos elou prá-
ticos. Sem chegar a essa aplicação do conhecimento científico raramente se poderá
dominar as teorias que o compõem. Porém, esse aspecto, basicamente técnico da
aprendizagem científica, não é suficiente para fornecer uma visão razoável do com-
plexo sistema representado por qualquer ramo do conhecimento, especialmente a
Física (ZANETIC, 1989, p. 17, grifo meu).

Uma das formas de promover uma aproximação razoável, entre física e cultura, contendo expressões de caráter artístico, social, cultural que a física possui, onde possam aparecer características da história e da filosofia da física, podem ser encontrados na articulação didática, entre a física e a literatura, principalmente no aspecto da leitura, inclusive de divulgação científica. Vários trabalhos, que serão apresentados em seguida, apontam para a construção e uso dessa ponte. Piassi (2011) evidencia algumas potencialidades educativas do uso da literatura no ensino de física, mais especificamente sobre a literatura presente nos romances de Arthur Clarke. $\mathrm{O}$ autor também destaca que na área de pesquisa em ciências existem muitos trabalhos voltados para o papel da leitura no ensino de ciências.

Como critério de busca de nossa revisão bibliográfica, baseamo-nos nos títulos e nos resumos dos trabalhos, compreendendo a produção desse século a respeito das investigações que tratassem de física e literatura, leituras/textos no ensino de física ou ciências, divulgação científica/ficção científica no ensino de física ou ciências, uso de analogias ou metáforas no ensino de física ou ciências. Ressaltamos a importância da definição do termo literatura, já apresentada e aceita por nós como critério para busca dos artigos dessa revisão bibliográfica. Os trabalhos foram separados em três categorias principais, como consta abaixo:

i. A leitura no ensino de ciências/física. Apresentamos as pesquisas que focam as relações entre física e literatura, ou que articulem a física com a leitura e com a literatura, mostrando seu potencial didático.

ii. O papel da divulgação científica no ensino de ciências/física. Nessa categoria apresentamos as pesquisas que tratam da divulgação científica, ficção científica e romances no ensino de ciências/física.

iii. A analogia e a metáfora no ensino de ciências/física. Nessa última categoria relacionamos as vantagens didáticas no uso de analogias e metáforas no ensino de ciências/física. 
Em nossa revisão bibliográfica, em cada uma das categorias acima, apresentamos as contribuições constantes nos estudos escolhidos, o que permite pequenos fechamentos sobre as pesquisas apresentadas ao longo do texto, ao invés de aparecerem apenas na forma de conclusão final, ou resultados. Essa opção de dialogar com as informações que vão surgindo ao longo do texto de forma a constituir pequenas conclusões é apoiada em Triviños (1987): “O denominado "relatório final" da pesquisa quantitativa naturalmente que existe na pesquisa qualitativa, mas ele vai se constituindo através do desenvolvimento de todo o estudo e não é exclusivamente resultado de uma análise última dos dados" (TRIVIÑOS, 1987, p. 131).

Ressaltamos que, alguns trabalhos, também apresentam o papel da história e filosofia no ensino de física em dimensões que se aproximam das relações entre física e literatura. Como por exemplo, em Lima (2012) o uso de textos históricos de Galileu Galei foi utilizado como recurso para o ensino da Cinemática. E, em Oliveira (2015) o poema para Galileo de Antônio Gedeão, pode ser utilizado em uma investigação histórica e filosófica sobre Galileu Galilei, permitindo, ainda, tratar de vários conceitos físicos ao longo do poema.

A Revista Brasileira de Ensino de Física, o Caderno Brasileiro de Ensino de Física, a Revista Ciência e Educação, a Revista Investigações em Ensino de Ciências, a Revista Eletrônica Enseñanza de Las Ciencias foram os periódicos consultados, dado sua importância no cenário de publicações de pesquisas em ensino de física. Pesquisamos também as Atas do EPEF, SNEF e ENPEC, além de outras revistas não especializadas em ensino de física, que porventura apresentassem artigos sobre o tema.

Salientamos que em nenhuma das revistas especializadas em ensino de física citadas foi encontrado algum trabalho que tratasse especificamente sobre Física e Literatura, sendo encontrados apenas em outras Revistas, não especializadas, e nas Atas de encontros/congressos. Em geral, as Revistas e Atas, específicas sobre ensino de física, apresentaram alguns trabalhos sobre a inserção de textos, de leitura, de divulgação científica ou de ficção científica e do uso de analogias. O que, a nosso ver, aproximam-se do uso da literatura no ensino de física. Esses trabalhos também foram incluídos em nossa revisão. Dada a escassez de trabalhos dentro do período pretendido foi necessário verificar algumas pesquisas, as quais julgamos importantes para nossa revisão, realizadas também no final do século passado.

\section{A leitura no ensino de Ciências/Física}

O papel da leitura e da palavra como representação de conceitos científicos/físicos pode ser explorado como uma possível ferramenta de interpretação, compreensão e contextualização de conceitos científicos/físicos, como apontam, ainda que com enfoques distintos, os trabalhos de Almeida, Silva e Machado (2001), Andrade e Martins (2006), Baker (1991), Barbosa-Lima e Carvalho (2003), Barcellos (2005), Briccia e Carvalho (2011), Carvalho e Zanetic (2004, 2005), Ferraz et al. (2001), Francisco Junior (2009), Giraldelli e Almeida (2008), Lima (2000), Lima (2012), Lima (2014), Lima (2015), Lima, Barros e Terrazzan (2004), Machi e Leite (2010), Menezes (2005), Moebus e Martins (2013), Nascimento e Barbosa-Lima (2006), 
Nigro e Trivelatto (2010), Norris et al. (2005), Padilha e Carvalho (2011), Paula e Lima (2010), Ricon e Almeida (1991), Silva e Almeida (2005), Souza, R. e Souza, P. (2005), Valente, Barcellos e Zanetic (2007), Zanotello e Almeida (2007).

Em Almeida, Silva e Machado (2001) é apresentada extensa bibliografia sobre as relações entre física e leitura. Esses autores relatam que o interesse por questões que envolvam a leitura no ensino de ciências não é recente nos pesquisadores da área. Avaliam as condições de produção de leitura, abordando a ideia principal de que a leitura propicia muito mais que apenas os produtos da ciência, suas leis e teorias, pois permite uma enculturação ampla do leitor, seu aumento de interpretação e associação da ciência em seus aspectos sociais, históricos e culturais. Apoiados na análise do discurso de Pêcheux (1990) e Orlandi (1999), a respeito das condições de produção da leitura, Almeida, Silva e Machado (2001), concluem que trabalhar a leitura em aulas de Física permite inserir contextos sociais e históricos, com potencial para se trabalhar a ciência como produtora de sentidos. Sua principal contribuição é a de mostrar que a leitura tem um papel importante na mediação da produção de conhecimento científico em um contexto mais amplo.

Questionamentos a respeito da aproximação entre leitura e física, verificando como o discurso científico-tecnológico é mediado pela leitura, além de reflexões a respeito da leitura no ensino e divulgação científica são analisados por Ricon e Almeida (1991), ao refletirem sobre o papel desencadeador da leitura nas aulas de física.

As autoras, Andrade e Martins (2006) investigam o sentido, que um grupo de professores de ciências atribui à leitura. Como resultado apontam o fato dos professores analisados no estudo não terem tido, tanto na sua formação inicial, quanto na continuada, oportunidades de refletirem sobre o papel da leitura no aprendizado e ensino de ciências. O que indica para necessidade de estudos que envolvam essas relações na formação dos professores de ciências.

É importante salientar que nesse trabalho, as autoras tomam como pressuposto que o professor seja um mediador, problematizando sua prática entre ensino de física e leitura. Tal medida é importante, pois a leitura por si só não se efetiva como propulsora de aprendizado científico, faz-se necessária a presença ativa do professor, mediando a leitura com o conhecimento científico almejado ao aprendizado discente, o que leva a uma problematização quanto a formação do professor, indicando a necessidade de se investigar ações leitoras tanto na formação de base dos professores, quanto na continuada.

Em Baker (1991) se investiga a compreensão de textos nos livros didáticos, avaliando a qualidade dos livros de ciência, a confiança do professor nesses livros e a comparação do sucesso de instrução baseada em livros textos com outras formas de instrução. O ganho qualitativo apresentado por esse autor se baseia na investigação sobre como melhorar a compreensão dos textos científicos, o que leva a necessidade de investigação quanto ao papel da leitura no ensino de ciências.

Barbosa-Lima e Carvalho (2003) avaliam positivamente o uso de uma história infantil com alguns conteúdos de física sobre máquinas simples, em especial a alavanca, para crianças 
do ensino fundamental, concluindo que através de narrativas o ensino de física é viável e também prazeroso aos estudantes. A autora Barcellos (2005) utilizando-se do texto "Uma abordagem quântica da condução elétrica em cristais de cobre", aproxima estudantes do EM da Física Quântica (FQ), constatando que, mais do que a compreensão do conteúdo específico e do seu significado formal, a atividade desenvolvida mostrou a potencialidade do texto como método de despertar o interesse pela ciência e compreender como ela é constituída.

Briccia e Carvalho (2011) apontam para importância do uso da história da ciência, mediante a leitura de texto sobre a natureza do calor, tal recurso contribuiu, também, para a alfabetização científica do grupo analisado na pesquisa.

Carvalho e Zanetic (2004) abordam as relações entre a leitura de textos históricos de física, textos de divulgação infanto-juvenil e o ensino da física moderna. Já em trabalho posterior (2005), os autores, para explorar a física moderna na sala de aula, adotaram a leitura de textos, por meio dos quais os alunos constroem imagens expostas em produções audiovisuais. A transformação das leituras em imagens possibilita ao aluno, conforme os autores, extrapolar os sentidos para construir os conceitos da Física Moderna já que estes não podem ser demonstrados de forma empírica, necessitando da imaginação e da abstração matemática para sua compreensão.

A ilustração dos conceitos explorados através da leitura também está presente no trabalho de Barbosa-Lima e Carvalho (2003) já citado, onde as crianças desenvolveram desenhos sobre a alavanca. A transposição de um conceito lido pelo aluno para uma figura, parece demonstrar a passagem de um conteúdo abstrato em concreto, dando sentido ao conceito, facilitando a assimilação e compreensão. Os trabalhos que tratam de analogias e metáforas, que serão apresentados mais adiante, exploram bem essa transposição.

A investigação sobre a dificuldade leitora dos alunos, pode ser verificada no trabalho de Ferraz et. al (2001), onde o problema principal parece ser o significado das palavras, apontando total desconhecimento, tanto por termos comuns da língua portuguesa, quanto por termos científicos, sendo estes ainda mais desconhecidos, prejudicando seu entendimento no estudo das ciências e, trazendo empatia por parte dos alunos por não conhecerem as palavras específicas do linguajar científico. Aqui é importante relembrar que Vygotsky (2008), já apresentava o significado de uma palavra como: "um amálgama tão profundo que não se poderia distingui-lo como pertencente ou ao pensamento ou à linguagem, sendo o significado de uma palavra o próprio conceito" (p. 151).

O trabalho de Souza, R. e Souza P. (2005), também aponta para os erros conceituais presentes em textos paradidáticos, concluindo que a maioria dos leitores não percebem os erros contidos na leitura. Entretanto, esses autores não levam em consideração o papel mediador do professor, sem o qual, obviamente, a leitura, de per si, pouco efeito trará aos alunos, no tocante ao desenvolvimento de conceitos físicos, se faz necessária a mediação do professor, buscando textos e leituras prazerosas que contenham um linguajar que aproxime os alunos dos conceitos científicos. 
Em Francisco Junior (2009), explora-se o uso da leitura no desenvolvimento de aspectos relacionados ao funcionamento da ciência, em especial a construção de modelos. $\mathrm{O}$ autor adaptou um capítulo de Imagens de um mundo quase imaginário, presente em Chassot (2003), verificando o papel da leitura e da escrita em alunos de Ensino Médio (EM) e pré-vestibular, chegando a conclusão de uma compreensão maior a respeito do funcionamento da ciência e do papel da imaginação na criação de modelos científicos. Nesse contexto a tese de doutorado de Lima (2000) analisa a introdução de um texto - Tão simples e tão úteis - para alunos da segunda série do Ensino Fundamental, concluindo, que a inserção do texto possibilitou uma participação ativa dos alunos nos problemas analisados, aumentando, inclusive o potencial discursivo, através do diálogo.

O uso de textos da segunda jornada do Diálogo de Galileu Galilei, foi utilizado por Lima (2012) como recurso para ensinar conceitos de Movimento Retilíneo Uniforme (MRU), nesse estudo o autor comprova a eficácia do texto histórico como recurso de ensino de física ao compará-lo com uma aula tradicional contendo apenas a exposição do conceito e uso de expressões matemáticas, constatando um aumento significativo na compreensão do conceito de MRU por aqueles que se utilizaram da leitura. Já na dissertação de mestrado de Lima (2014), a literatura foi articulada com a física por meio da abstração, o autor inova, preenchendo uma importante lacuna nos estudos sobre física e literatura, que trata de apontar a literatura como motivadora e desenvolvedora da abstração, tornando-a uma possível ferramenta ao ensino de física, desde que o professor assuma seu papel de mediador. Nesse mesmo contexto, Lima (2015), trabalha a literatura como ferramenta no ensino de Mecânica Quântica com alunos do EM por meio da leitura do livro Alice no País do Quantum de Gilmore (1998), verificando maior compreensão e interesse pela física e apontando para necessidade de estudos teóricos que investiguem a fundo essa motivação e aprendizagem maiores, quando a física é ensinada por meio da literatura, ao invés do constante repisar de exercícios de repetição.

No artigo de Lima, Barros e Terrazzan (2004) os autores promovem um encontro entre o ensino de física e a poesia, explorando fatores presentes em Mensagem de Fernando Pessoa, onde se articula a imaginação, a leitura e a interpretação com o ensino de física, apresentando elementos iniciais ao estudo da física, como o papel e utilização dos símbolos. A interpretação textual, também é explorada em Giraldelli e Almeida (2008) ao promoverem uma leitura coletiva sobre texto infanto-juvenil para alunos entre 09 e 10 anos de idade, comprovam a eficácia da leitura como geradora de sentidos, além do prazer dos alunos em realizar a atividade, o que possibilitou, por meio da mediação entre professor-aluno e aluno-aluno, a apreensão de conhecimento científico. A leitura possibilita a construção de significados científicos, que subsidiam práticas posteriores do professor, como o ensino de conceitos físicos, como apresentado por Zanotello e Almeida (2007), ao trabalharem com a leitura de um livro sobre a vida e obra de Isaac Newton. 
Em Machi e Leite (2010), as autoras fazem um levantamento sobre trabalhos que abordam o papel da leitura no ensino de física, avaliando a escassez desses estudos nos periódicos analisados por elas e a falta de trabalhos que tratem da formação de professores como mediadores do processo de leitura e ensino de física, apontando para a necessidade de maiores publicações sobre o tema e estudos teóricos sobre suas relações. Os periódicos verificados pelas autoras são apresentados, assim como o período verificado que se encontra entre parênteses: Ciência \& Educação - UNESP (1998 a 2009), Revista Brasileira de Pesquisa em Educação em Ciências - ABRAPEC (2001 a 2009), Investigações em Ensino de Ciências - UFRGS (1996 a 2009), Caderno Brasileiro de Ensino de Física (1984 a 2010), Revista Brasileira de Ensino de Física (1979 a 2009), Ciência \& Ensino - UNICAMP (1996 a 2008), Ensaio: Pesquisa em Educação em Ciências - UFMG (1999 a 2010).

A respeito dos estudos teóricos, é notável a sua ausência no ensino de física nacional. Em geral, encontramos o desenvolvimento e maior envolvimento teórico, inclusive, com outras áreas do conhecimento, em publicações internacionais, como em Norris et. al (2005), que possuem uma publicação na Science Education onde apresentam um quadro teórico para explicar o papel de narrativas presentes na ciência.

A constatação apresentada por Machi e Leite (2010) remete a necessidade de estudos que investiguem o motivo da não publicação de trabalhos que tratem das relações entre leitura e física em revistas especializadas em ensino de física. Esses periódicos não aceitam esses trabalhos? Não se consideram a relevância e o potencial didático e metodológico entre a leitura e a física? Ou, os autores não estão submetendo seus trabalhos a essas revistas? Essas são apenas algumas questões que merecem atenção dos pesquisadores.

Outra pesquisa que aponta a falta de investigações e desenvolvimento teórico que explique as relações entre leitura e alfabetização científica está presente em Moebus e Martins (2013). Essas autoras apresentam um levantamento bibliográfico de artigos publicados entre 2008 e 2012, a respeito da leitura e alfabetização científica, em quatro periódicos eletrônicos nacionais e quatro periódicos eletrônicos internacionais com classificação nível A. Os periódicos analisados foram: Revista Brasileira de Pesquisa em Educação em Ciências (RBPEC), Ensaio - Pesquisa em Educação em Ciências, Ciência e Educação, Investigações em Ensino de Ciências, International Journal of Science Education, Research in Science Education, Science and Education e Enseñanza de las Ciências. As autoras focam nas relações entre leitura e alfabetização/letramento científico, verificando a escassez de trabalhos e a falta de estudos teóricos que aprofundem a discussão conceitual sobre essas relações.

Quanto ao termo alfabetização científica ou letramento científico, Sasseron e Carvalho (2011), expõem uma pesquisa bibliográfica mais abrangente, em âmbito nacional e internacional, partindo de uma leitura histórica sobre os termos e como eles vem sendo tratados pelos pesquisadores. Essas autoras identificam, por meio de sua revisão bibliográfica, o que chamam de eixos estruturantes da alfabetização científica, divididos em três partes: compreensão básica 
de termos, conhecimentos e conceitos físicos fundamentais; compreensão da natureza das ciências e dos fatores éticos e políticos que circundam sua prática e; entendimento das relações existentes entre ciência, tecnologia, sociedade e meio-ambiente.

De acordo com Sasseron e Carvalho (2011), as propostas didáticas que envolvem esses eixos podem promover o início da alfabetização científica dos alunos. Embora não tenha sido objetivo das autoras, a investigação de práticas ou materiais didáticos que contemplem esses eixos, a fim de subsidiar o professor de ensino básico, bem como, abordá-los dentro da formação inicial ou continuada dos professores por meio da leitura de textos científicos e de divulgação científica, pode trazer gratas surpresas por guardar um potencial estratégico de ensino que pode fomentar a alfabetização científica.

A respeito da leitura, há de se considerar, também os livros, tanto de divulgação científica, com possibilidades interessantes, como apresentado em Silva e Almeida (2005), que verificam o uso desses textos em aulas de física, quanto os livros didáticos, que, apesar de raros, como A Matéria Uma Aventura do Espírito, Menezes (2005), tratam a física pelo viés da leitura, tornando-se importantes ferramentas de aprendizagem, com potenciais enormes de ensino, além do aumento no interesse pela física por parte dos alunos, o que se constata também em Pessoa Junior (2003), que apresenta uma abordagem mais intuitiva e menos matemática, abordando e enfrentando os problemas conceituais e filosóficos da física quântica.

$\mathrm{O}$ uso de tais estratégias de ensino agrada tanto aos adolescentes de EM quanto as crianças, como se pode verificar na pesquisa-ação de Nascimento e Barbosa-Lima (2006), feita com alunos do EF de uma escola municipal do Rio de Janeiro. Na pesquisa, o uso de histórias infantis contendo conteúdos de física ajuda os alunos a construírem conhecimento científico. A proposta, também se tornou agradável e prazerosa aos alunos, contribuindo para o aumento da curiosidade das crianças.

Em Nigro e Trivelato (2010) a leitura é avaliada sob a perspectiva cognitiva-processual, por meio da compreensão leitora de grupos de alunos de 14-15 anos, com diferentes gêneros, sobre textos de divulgação científica e livro texto a respeito da doença genética anemia falciforme. Os resultados apontam para melhor compreensão e resultados por parte dos alunos que leram o material de divulgação científica, do que o grupo que leu trechos do livro texto. Na pesquisa de Padilha e Carvalho (2011) são apresentadas as relações entre palavras e gestos usados por alunos do EF como representações de conceitos científicos. Apontam para necessidade de estudo de outras ferramentas cognitivas usadas pelos alunos no momento da interpretação de um conceito e para facilitação do processo de significação das palavras dentro de um contexto científico escolar.

No trabalho de Paula e Lima (2010) são explicitadas concepções de linguagem, de leitura, de ciências e de ensino de ciências, de modo a caracterizar e avaliar uma forma específica de mediação da leitura de textos didáticos de ciências. Demonstra-se que aprender ciências implica na apropriação de modos canônicos (normativos) de interpretação e pensamento. Sendo ressaltada a importância do professor de confrontar as múltiplas interpretações possíveis, de um 
dado texto, com uma interpretação padronizada, que expressa o ponto de vista da comunidade científica. Ou seja, salienta-se a necessidade de atuação do professor como mediador do processo articulador entre as leituras e o ensino de ciências.

Valente, Barcellos e Zanetic (2007) apresentam um texto visando explorar as várias facetas de Einstein de forma lúdica. A principal potencialidade do texto se traduz no tipo de abordagem, que permite fazer pontes entre o conhecimento físico e outros tipos de conhecimento, além de trazer uma visão de ciência mais ampla e contextualizada com a sociedade.

Vale ressaltar que uma importante publicação sobre essa temática, leitura e ensino de ciências, foi lançada no Journal of Research in Science Teaching (1994), em número especial, chamado de "The Reading - Science Learning - Writing Connection", cujos artigos tratam das relações entre ensino da ciência e leitura e produção da escrita. Os artigos somam onze produções, a saber: Holliday et al. (1994), Alexander e Kulikowich (1994), Baker e Saul (1994), Fellows (1994), Gaskins et al. (1994), Glynn e Muth (1994), Hynd et al. (1994), Keys (1994), Norris e Phillips (1994), Rivard (1994), Spiegel Junior e Barufaldi (1994).

Os trabalhos específicos que tratam da física e literatura demonstram a literatura como possível meio de se ensinar conceitos científicos, despertando a curiosidade e a imaginação dos estudantes, além de propiciar maior estímulo no estudo de temas científicos como se verifica nos trabalhos de Menezes e Guerra (2009) e Guerra e Menezes (2009) que utilizam obras literárias para contextualizar conceitos físicos com os alunos. Lopes e Salomão (2009) demonstram uma potencialização da aprendizagem científica por meio da literatura, além de um maior estímulo por parte dos estudantes aos estudos de temas científicos, como aparece, também em Pinto e Raboni (2005) ao explorarem possibilidades científicas na literatura brasileira.

As relações entre a física e a literatura enquanto arte, como processo de criação e imaginação, como já apresentado, podem ser verificadas em várias facetas, como na pintura, no teatro, na letra de uma música, ou em um poema, indicando variáveis culturais importantes para o ensino de física. Essas vertentes são exploradas e apresentadas por Brito e Reis (2015), Guerra, Braga e Reis (2003), Oliveira (2015), Nory e Zanetic (2005), Zanetic (1989, 1996, 1997, 1998 2002, 2005, 2006, 2007, 2009). Nesse contexto, Lima; Barros e Terrazzan (2004), já citados anteriormente, articulam a imaginação, a leitura e a interpretação com o ensino de física. Através da leitura e interpretação de um poema visual, Fonseca, Andrade e Silva (2015), propõem atividade didática sobre elementos de física térmica e constatam que articular a física com a literatura contribui para a leitura dos alunos, com possibilidades de compreensão e problematização da física em contextos diversos, despertando o interesse pela física. Essas aproximações também podem ser encontradas e verificadas em Guerra e Menezes (2010) onde a literatura é apresentada como caminho para o ensino de conceitos científicos, possibilitando também o despertar da imaginação por parte dos alunos.

A convergência entre a literatura universal e o ensino de física, contendo elementos da história da física é explorada por Zanetic (1996) ao indicar influências entre grandes escritores a partir do alvorecer da física clássica no século XVI e grandes cientistas como Galileu, 
Newton e Einstein. O uso de textos históricos de Galileu Galilei, no ensino de Mecânica para alunos de EM foi abordado por Lima (2012). No estudo de caso realizado por Schiffer e Guerra (2011), a utilização da ferramenta Narrativas Históricas permitiu a inserção da História e Filosofia da Ciência (HFC) ao se trabalhar o conceito de energia com alunos do $9^{\circ}$ Ensino Fundamental (EF). Relações entre a física e a literatura, por meio de extratos de filosofia da ciência, estão presentes em Custódio Pinto e Zanetic (2000). Em Campos e Ricardo (2014) encontramos as concepções do mundo celeste segundo Aristóteles, possibilitando ao professor de física um respaldo histórico-filosófico ao trabalhar as visões de mundo geocêntricas e heliocêntricas, geralmente presentes nos capítulos que tratam das leis de Kepler e Gravitação Universal dos livros didáticos.

Tais estudos nos indicam que, tanto a história da física, quanto a filosofia da física, podem ser exploradas como pertencentes às relações didáticas entre física e literatura, com potenciais de ensino que possibilitem uma inserção da física nos contextos culturais mais amplos, do qual ela, a física, também faz parte. Conforme Pessoa Júnior (1996): "Sem dúvida a história da ciência torna o curso interessante, mas além de ajudar no aprendizado, ela pode ajudar os alunos a entender para que estudar ciências" (PESSOA JUNIOR, 1996, p.04). De acordo com esse autor é preciso estabelecer as razões, os motivos e os objetivos de se ensinar física. Caso se escolha ensinar física para que nossos alunos compreendam como se faz ciência, para que tenham uma visão científica do mundo, para que possam ser capazes de verificar como a física gera a tecnologia que usam cotidianamente e, como ela se relaciona com outras áreas do conhecimento, influenciando cientistas e não cientistas, então, a história e a filosofia da física são fortes candidatas como recursos didáticos para esses fins (PESSOA JUNIOR, 1996).

\section{O papel da divulgação científica no ensino de Ciências/Física}

Outra temática ligada ao estudo de leituras de textos no ensino de ciências aparece denominada como divulgação científica. Nascimento e Rezende Junior (2010) realizaram uma importante revisão de literatura no período de 1997 a 2007, apontando que os estudos sobre esse tema se restringem ao funcionamento dos textos e seu sentido pelos sujeitos leitores em diferentes níveis de ensino. Alertam que poucos estudos têm se preocupado com a discussão, na formação inicial, dos aspectos relacionados à divulgação científica, ou sobre as interações discursivas entre futuros professores e esses textos. Os autores alertam para a necessidade de estudos teóricos, a fim de investigar as relações entre o uso da divulgação científica e o ensino formal de ciências, uma vez que se constata que a divulgação científica é uma prática corrente entre os professores de ciências, porém seu potencial didático não é explorado na formação inicial dos professores. Por fim, Nascimento e Rezende Junior (2010) criticam a dicotomia entre o baixo nível de publicações nos periódicos nacionais e internacionais e o número de trabalhos sobre a divulgação científica nos trabalhos de mestrado e doutorado. O que implica que esses trabalhos não estão sendo publicados em forma de artigos nas principais revistas de ensino de ciências. 
Outro levantamento bibliográfico foi realizado por Puiati, Borowsky e Terrazzan (2007), os autores verificaram as produções sobre divulgação científica apresentadas nos ENPEC (Encontro Nacional de Pesquisa em Educação em Ciências), entre os anos de 1997 e 2005, verificando uma oscilação quanto a quantidade de trabalhos sobre o tema, sendo baixa nas primeiras edições do ENPEC, com leve crescimento na $3^{\text {a }}$ edição e queda nas últimas edições. Os autores constatam um grande potencial para pesquisa na divulgação científica. Primeiro, pelo fato de os alunos demonstrarem interesse e motivação em sua utilização. E, segundo, o fato de os professores recorrerem constantemente a diversas fontes de divulgação científica como apoio às atividades desenvolvidas em sala de aula. Entretanto, esses professores não possuem facilidades em encontrar materiais organizados para uma correta utilização, o que indica a necessidade de maiores investigações sobre o papel da divulgação científica, bem como a produção de material didático apropriado para aporte aos professores em suas atividades didáticas.

Chaves, Mezzomo e Terrazzan (2001) apresentam uma proposta de inserção da FMC através de materiais de divulgação científica. Conforme os autores, os professores envolvidos na mediação texto-aluno percebem a importância da inserção de materiais de divulgação científica, mas alertam para a dificuldade deles em identificar os conceitos físicos nos textos selecionados, o que aponta para uma possível dificuldade leitora e interpretativa, também, pelos professores, o que pode se justificar pela falta de ações de leitura nas aulas de física, sendo necessário que mais trabalhos que envolvam a leitura de textos de divulgação no ensino e aprendizagem científica venham a se concretizar, inclusive, na formação de professores. Nessa perspectiva, Dias e Almeida (2009) investigam o papel do jornalismo científico em textos de divulgação científica com alunos de licenciatura em física ao lerem textos das revistas Ciência Hoje e Pesquisa Fapesp, verificando a atração do leitor pelos recursos empregados na escrita desses textos.

A investigação de tipos de textos escritos, com enfoque na divulgação científica, pode ser encontrada em Almeida e Ricon (1993) e Almeida (1998) onde ressaltam o desenvolvimento cultural dos alunos, e que o texto escrito, além de estar presente na escola em seu uso tradicional de transmissão de conteúdos e informações, pode também provocar reflexão e mudar representações, sendo um mediador de conhecimentos, como apresentado por Silva e Almeida (2005), ao investigarem a utilização de textos de divulgação científica no deslocamento do discurso pedagógico autoritário, privilegiando uma formação científica mais ampla, permitindo aos estudantes certa produção de sentido sobre a leitura realizada. A esse respeito, Almeida e Queiroz (1997), desenvolveram atividade de leitura de partes de livro de divulgação científica escrito por Einstein e Infeld, com estudantes adultos, gerando conhecimento escolar e possibilitando investigar como esses textos e leituras são interpretados pelos alunos. Nesse contexto, Decian, Correia e Sauerwein (2015), desenvolvem atividades de escrita nas aulas de física com o apoio da divulgação científica.

Para Monteiro, Gaspar e Monteiro, (2005), a leitura de textos de divulgação científica possui um papel desencadeador de motivação no leitor, pois sua linguagem é mais acessível, 
possibilitando um gosto maior por parte dos alunos no estudo da física. De acordo com Strack, Loguércio e Del Pino (2009), a leitura de divulgação científica guarda um potencial enorme de pesquisa e um possível espaço para inserção de novos saberes pautados em conceitos, percebendo-se a existência de uma motivação geradora pelas leituras.

Pinto e Raboni (2005) realizam um estudo exploratório sobre as concepções científicas em livros de divulgação, classificados por editores como literatura infantil. Na pesquisa os autores relatam sobre a falta de estudos sobre o tema, além de apontar para os benefícios na aprendizagem das ciências quando se aproximam a literatura infantil e o ensino de ciências, possibilitando melhor aprendizado científico e desenvolvimento da habilidade leitora por parte dos estudantes.

A utilização da literatura de ficção científica, da leitura de textos de ficção científica e romances no ensino de física, possui vários aspectos a serem explorados enquanto divulgação científica. Esse tipo de pesquisa relacionada com o ensino de física se verifica em Piassi (2007), que se utiliza de vários filmes e contos de ficção científica no ensino de física. Lima (2014) usa o livro Alice no País do Quantum, no ensino e aprendizagem de Mecânica Quântica para alunos do EM, Pereira e Londero (2013) também se utilizam de Alice no País do Quantum no ensino de partículas elementares. Silveira (2010), por sua vez, usa a obra de Monteiro Lobato para relacionar o ensino de ciências e a literatura.

Nesse contexto, Neto (2004) e Vierne (1994), estabelecem ligações entre o ensino de ciências e as obras de ficção de Júlio Verne. Para Vierne (1994) a obra de Júlio Verne vai além da conquista de leitores, ela - a obra de Júlio Verne - participa da constituição de uma concepção de mundo que, em alguns casos, tornar-se-á um marco nas vidas de seus leitores.

Um desses efeitos é de certa maneira direto, e corresponde ao objetivo manifestado pelo editor e pelo seu autor: muitos exploradores e cientistas confessam ter descoberto a sua vocação através da leitura adolescente dos romances de Júlio Verne (VIERNE, 1994, p. 88).

Dentre alguns, cuja vocação, paixão, ou motivação se desenvolveu pela leitura de Júlio Verne, encontram-se o cientista alemão Hermann Julius Oberth (1894 - 1989), que ao ler "Da Terra à Lua" teve seus interesses voltados à exploração espacial, sendo o primeiro a idealizar foguetes com múltiplos estágios, além de pensar em estações espaciais. Em sua autobiografia escreveu: "Tinha onze anos quando recebi de presente de minha mão os célebres livros de Jules Verne, que já li ao menos cinco ou seis vezes, até os saber de memória”. Além desses feitos, Oberth também se dedicou a literatura, escrevendo livros como Primer For Those Who World Govern. O russo Konstantin Edwardovitch Tsiolkovisky (1857-1935), também teve influência dos escritos de Verne para seus estudos na cosmonáutica, como afirma, segundo Mourão (2000):

Durante muito tempo pensei no foguete como todo mundo, considerando-o apenas um meio de diversão, com algumas aplicações pouco importantes na vida corrente. 
Não me lembro exatamente quando me veio a ideia de fazer os cálculos dos seus movimentos. Provavelmente, os primeiros germes dessa ideia foram fornecidos pelo fantástico Júlio Verne e, em consequência deste grande autor, meu pensamento orientou-se nesta direção, estimulando o desejo que, mais tarde, impulsionou o espírito do meu trabalho (TSIOLKOVISKY, apud MOURÃO, 2000, p. 1).

Vários outros, só para citar exemplos, sofreram influência direta da literatura de Verne e da ficção científica, como o engenheiro norte-americano Robert Hutchings Goddard (18821945), desenvolvedor da moderna tecnologia dos foguetes, e o engenheiro Wernher Von Braun (1912-1977), responsável pelos primeiros lançamentos de satélites e foguetes norte-americanos. Diversos outros cientistas das áreas de física, química e biologia, também sofreram forte influência da leitura de ficção científica em suas vidas, o que aponta para seu forte potencial pedagógico (MOURÃO, 2000).

O uso de textos de divulgação/ficção científica, romances e contos literário não se resume à física. $\mathrm{O}$ ensino da matemática também pode se influenciar das relações entre a leitura e o desenvolvimento de conceitos matemáticos abstratos. Em Teixeira e Mendes (2006), estabelecem-se as relações matemáticas presentes na obra Alice no País das Maravilhas. Esses autores, também propõem formular proposições argumentativas favoráveis ao uso eficaz de romances matemáticos na construção do conhecimento.

Outros trabalhos, como de Flôr e Cassiani (2011), Kemper, Zimmermann e Gastal (2010), Silva et al. (2015), mostram que uma linguagem mais acessível ao conhecimento científico pode facilitar a transposição didática de conceitos e desenvolver a abstração. Indicam, para a necessidade de formar professores, também leitores, para que se possa mediar a leitura em sala de aula de forma a garantir um aprendizado em física mais significativo. Alertam que poucos estudos têm se preocupado com a discussão, na formação inicial, dos aspectos relacionados à divulgação científica, ou sobre as interações discursivas entre futuros professores e esses textos. Mostram que os professores não têm tido, tanto na sua formação inicial, quanto na continuada, oportunidades de refletirem sobre o papel da leitura no aprendizado e ensino de ciências. Verificam que a divulgação científica é uma prática corrente entre os professores de ciências, porém seu potencial didático não é explorado na formação inicial destes. Concluem, portanto, sobre a necessidade de estudos teóricos, a fim de investigar as relações entre o uso dessas leituras e o ensino formal de ciências.

Conforme Flôr e Cassiani (2011), entre outros fatores, mostram que, por mais que a linguagem científica busque a neutralidade, iluda-se com a transparência, ainda assim ela é metafórica e utiliza-se de comparações e analogias para comunicar, o que, também, se verifica em Mecke (2004). No trabalho de Flôr e Cassiani (2011) verificamos uma importante relação dos professores com a leitura, apontando para necessidade de melhor preparo dos professores para lidar com questões de linguagem, procurando deixar claro aos alunos o que são representações, metáforas e analogias usadas na elaboração de modelos e nas explicações de conceitos científicos, a fim de se evitar o mau uso desses recursos. 
Com base na análise de discurso de Michel Pêcheux, Silva e Almeida (2013) investigam uma proposta didática com alunos de Ensino Médio sobre a leitura do texto de divulgação científica: A Ressonância Magnética Nuclear - RMN-e suas aplicações atuais de Bonagamba, Capelle e Azevedo (2005). Verificam que os alunos tiveram dificuldades leitoras e certa recusa em realizar as atividades propostas, identificando que o texto escolhido continha um linguajar muito sofisticado aos alunos o que, conforme os autores, demonstra a urgência em se trabalhar leituras nas aulas de física, além de maior promoção do papel mediador do professor para que se trabalhe formas de cativar os alunos para a realização de trabalhos que articulem a leitura e a física.

Em trabalho posterior, sobre essa dificuldade apresentada pelos alunos na leitura desse texto específico, Silva e Almeida (2014) constatam que, apesar do tema da leitura ter sido escolhido pelos alunos, e apesar do texto ser considerado de divulgação científica, os termos científicos, desconhecidos pelos alunos e a escrita sofisticada, geraram repulsa e recusa da leitura, bem como posterior trabalho em sala, o que aponta para a necessidade de se escolher bem o tipo de leitura a ser apresentada aos alunos. Aparentemente não basta ao texto ter uma classificação de divulgação científica, sua escrita e apresentação deve conter um diálogo próximo ao leitor, sem sofisticações técnico-científica que apenas leitores alfabetizados cientificamente possam compreendê-lo.

No artigo de Ramos e Piassi (2013) é possível verificar uma possibilidade de resposta à aflição citada acima por Silva e Almeida $(2013,2014)$ em relação a dificuldade leitora dos alunos. A leitura sobre RMN utilizada, apesar de ser de divulgação científica, pode ter sido considerada chata pelos alunos, o que dificultou a leitura e a recusa, por parte de alguns alunos, em realizar as atividades propostas. Já, no trabalho de Ramos e Piassi (2013), o livro utilizado: O Guia dos Mochileiros das Galáxias, apresenta um sabor cômico/irônico em sua leitura, desprendendo, de acordo com esses autores, um interesse maior dos estudantes ao lê-lo. Embora, apenas alguns alunos tenham elaborado relações críticas entre a obra e a ciência, os autores afirmam que os alunos gostaram da leitura. Tal constatação pode levar a um dado importante nas relações entre física e leitura. A de que é necessário mediar o tipo de leitura a ser apresentada aos alunos, a fim de gerar interesse pelos estudos pretendidos.

De acordo com Silva e Almeida (2013), uma das dificuldades apresentadas pelos alunos foi em relação ao entendimento do spin, embora explicado no texto, os alunos demonstraram não entender seu conceito. O que pode afirmar a necessidade de escolha adequada do texto a ser apresentado aos alunos, que contemple outras formas de apresentação do conceito, além da explicação textual do mesmo. Nesse sentido, encontramos em Lima (2014) o uso de ilustrações, presentes no livro Alice no País do Quantum utilizado em sua pesquisa de mestrado, que mostram os elétrons representados com guarda-chuvas para cima e para baixo, ajudando os alunos a identificar melhor o conceito de spin, além do texto escrito.

Essa possibilidade de melhorar o entendimento conceitual por parte dos alunos, que vai além do texto escrito, pode ser evidenciada pelos aspectos gerais presentes na literatura, 
como a utilização na escrita de desenhos, figuras, ilustrações, analogias, metáforas, entre outros recursos de linguagem não verbal, que juntos, e não insólitos, possibilitam o uso da multimodalidade nos textos, garantindo um entendimento maior sobre o conceito a ser trabalhado com os alunos.

Nessa perspectiva, Pereira e Terrazzan (2011) verificam o uso da multimodalidade em textos de divulgação científica, constatando que os alunos apresentam uma melhor compreensão conceitual dos conceitos trabalhados nos textos, além da dificuldade, por parte dos professores, em deixar de atuar de maneira tradicional monomodal, o que indica a defasagem na formação inicial e continuada dos professores em leitura e interpretação multimodal. A fim de investigar com maior profundidade essas relações, os autores, promovem um grupo de estudos sobre o ensino de ciências e a multimodalidade, com seminários de estudos e elaboração de módulos didáticos para serem aplicados em sala de aula, o que corrobora com uma solicitação frequente dos professores, materiais didáticos que contenham as propostas inovadoras de ensino.

A falta de preparo dos professores na utilização de textos de divulgação científica com seus alunos é frequentemente verificada como uma espécie de insegurança, o que demonstra que não tiveram nem em sua formação inicial, nem na continuada, condições de trabalhar com esses textos, o que pode indicar que a mesma insegurança pode estar presente nos professores de Ensino Superior (ES), nos cursos de licenciaturas, sejam de física, química ou biologia, onde se verificam, geralmente, a utilização tradicional e monomodal de ensino, por meio da utilização de livro didático e listas de exercícios.

Nesse contexto, encontramos em Terrazzan, Gabana e Lunardi (2003), a elaboração de roteiros com textos de divulgação científica para professores do EM, juntamente com o alerta de que o texto por si só não garante sua utilização, sendo necessário que os professores tenham condições e preparo para sua utilização a fim de diminuir sua insegurança, fomentando discussão em aula com os alunos e colaborando para o processo de leitura e interpretação textual. A utilização, no ensino de física, que apresente o potencial didático, nos textos de divulgação científica pode ser encontrado em Terrazzan (2000).

Os poucos trabalhos que apresentam alguma crítica a respeito do uso de leituras, apontam para os erros conceituais existentes nos livros de divulgação científica, ou paradidáticos (SOUZA, R; SOUZA, P, 2005). Entretanto, nesses casos, esquecem-se de uma particularidade muito importante: investigar e levar em consideração o papel mediador do professor no uso de recursos literários no ensino de ciências. Sem essa mediação, a leitura, por si só, pouco oferecerá em termos de aprendizado científico, o que aponta para a necessidade de inserir na formação de professores de física, recursos literários, em conjunto com os conteúdos específicos da disciplina.

Tal necessidade se manifesta na constatação de que os professores de ciências, em geral, aparentam ter uma possível dificuldade leitora e interpretativa, o que pode se justificar 
pela falta de ações de leitura nas aulas de física, sendo necessário que mais trabalhos que envolvam a leitura de textos no ensino e aprendizagem venham a se concretizar como indicado por Chaves, Mezzomo e Terrazzan (2001) e Machi et al., (2010).

Outros autores, como Strack, Loguércio e Del Pino (2009) destacam que há um bom número de professores de ES que não inserem leituras de textos em suas aulas, por falta de tempo, tanto em lecionar, quanto em cumprir o programa dos conteúdos, pois se veem obrigados a ler e publicar artigos em demasia, não sobrando tempo para leituras em sala de aula. Admitem que seria bom inserir leituras durante as aulas, mas se veem impedidos. Todavia, apesar desses impedimentos, acreditam que a leitura guarda um potencial enorme de pesquisa e um possível espaço para inserção de novos saberes pautados em conceitos, percebendo-se a existência de uma motivação geradora pelas leituras.

\section{A analogia e a metáfora no ensino de Ciências/Física}

Assim como a literatura constitui-se por seu aspecto escrito, textual, também ela é considerada uma arte, com dimensão criadora, onde há beleza e poesia envolvidas. Diante disso, a literatura também se utiliza de figuras de linguagem, o que contribui para a estética em sua escrita, dessas figuras de linguagem, verificamos que as metáforas e as analogias são muito utilizadas pelos pesquisadores da área de ciências, sendo, portanto, consideradas nessa terceira parte de nossa revisão bibliográfica sobre física e literatura.

Uma metáfora, no seu sentido linguístico, significa o emprego de uma palavra ou uma expressão, com o intuito de produzir sentido figurado ao estabelecer uma relação de comparação entre dois termos, embora, como já apresentado em Mecke (2004) e Lakoff e Johnson (1980), a utilização de metáforas como recurso literário empregado no ensino de ciências, possibilita a abstração dos conceitos físicos. Enquanto a analogia consiste na aproximação de dois domínios heterogêneos, como um conceito científico a ser entendido, chamado de 'alvo' que se torna compreensível por semelhança com outro domínio mais conhecido, chamado de 'análogo' (GLYNN et al., 1998).

Assim, o uso de uma metáfora adequada aproxima-se do elemento real que interessa ao pesquisador/professor. O grande valor pedagógico do uso de figuras de linguagem consiste em saber transferir seu potencial de aprendizado e compreensão, conforme apresenta Ortony (1975), daquilo que é conhecido para o que é desconhecido, como o caso de um conceito físico, sendo explicado por um experimento de pensamento.

A edição especial do Journal of Research in Science Teaching, de 1993, trata exclusivamente de pesquisas sobre analogias, intitulada O papel da Analogia na Ciência e no Ensino de Ciência, onde podemos encontrar, dentre outros fatores, aspectos teóricos e de conexão com outras áreas do conhecimento, como o estudo sobre como a analogia propicia um aumento significativo da taxa de retenção e de aprendizagem, através da investigação dos princípios de modelagem neural de Grossberg, fazendo com que, segundo os autores, a aprendizagem se instaure (LAWSON; LAWSON, 1993). Nessa edição também constam os trabalhos de Brown 
(1993), Clemente (1993), Harrison e Treagust (1993), Lawson (1993), Schwartz (1993), Stavy e Tiroshi (1993), Sutton (1993), Wong (1993).

Uma ferramenta teórica importante sobre o uso de analogias, denominada de Teaching With Analogies (TWA) foi proposta por Glynn, Law, Gibson e Hawkins (1998) e trata de um modelo capaz de orientar os professores a criarem analogias eficazes aos seus alunos. A TWA se baseia em seis passos que devem ser levados em consideração ao se ensinar com analogias: introduzir o assunto-alvo; identificar características relevantes entre o conceito alvo e o análogo; mapear as semelhanças entre os dois domínios (alvo e análogo); indicar onde a analogia falha e; esboçar conclusões. A fim de melhorar a TWA, Harrison e Treagust (1993 e 1994) buscam sistematizar o ensino com analogias e diminuir a formação de concepções alternativas, aumentado a compreensão por parte dos alunos. Para tanto, sugerem o uso dos seis passos da TWA na ordem adequada ao ensino e estilo do professor, bem como a observância das características do conceito científico e do análogo que está sendo utilizado.

Sobre a publicação de trabalhos nacionais sobre o uso de analogias, encontramos em Nunes, Ferraz e Justin (2007) a investigação de 1021 trabalhos verificados em três edições do ENPEC e das revistas Ciência e Educação e Ensaio, entre os anos 1999 e 2004. Os autores constataram que apenas 18 trabalhos, o que corresponde a menos de $2 \%$ em seis anos de produção acadêmica, tratavam de analogias como objeto de estudo. Ressalta-se a dicotomia entre o uso frequente de analogias por parte dos professores, além de sua presença esparsa e caótica (TERRAZZAN et. al, 2000) nos livros/materiais didáticos, e a escassez de trabalhos que investiguem seu uso com profundidade no ensino brasileiro, mostrando uma grande pobreza de pesquisas sobre o tema e uma gama de potencial área para futuras pesquisas.

Ainda sobre o estudo de analogias no ensino de ciências/física a nível nacional, encontramos no pesquisador Terrazzan e seus colaboradores extensos trabalhos, tanto de aplicação de analogias em contextos específicos de conteúdos científicos, seja para o EM ou para formação continuada de professores, quanto investigações de análogos em construção de conhecimento ou aplicados em livros didáticos, esses estudos, embora com contextos e aplicações distintas, resultam em um escopo investigativo interessante aos pesquisadores que quiserem se debruçar sobre as relações entre ensino de ciências e o uso de analogias. Alguns desses trabalhos podem ser verificados em Ferraz e Terrazzan (2001), Ferraz e Terrazzan (2002), Ferraz e Terrazzan (2003), Silva, Pimentel e Terrazzan (2011), Silva e Terrazzan (2005), Silva e Terrazzan (2011), Terrazzan (1996), Terrazzan et al., (1999), Terrazzan et al., (2000), Terrazzan e Feltrin (2000), Terrazzan, Pimentel, Silva e Amorin (2005), Zambon e Terrazzan (2010), Terrazzan e Santos (2003), Terrazzan, Schmidt e Silveira (1997) e Terrazzan, Silveira e Schmidt (1997).

Almeida (2004) trabalha com trechos de falas de cientistas da área da física, como Albert Einstein e Werner Heisenberg mostrando funcionamentos diversificados da linguagem na produção da ciência. Em um dos trechos destacados pela autora, Heisenberg considera que:

O fato de que vocábulos possam desencadear, em nossa mente, imagens numerosas e semi-conscientes pode ser utilizado para repensar, na linguagem, partes da realidade 
de maneira muito mais clara do que as construções lógicas por si só propiciam (HEISENBERG apud ALMEIDA, 2004, p. 79).

Verificamos nessa fala, que Heisenberg explica a importância das analogias para a compreensão de conceitos abstratos (ALMEIDA, 2004). A necessidade de se buscar uma linguagem próxima ao aluno, menos técnica e que possa garantir uma compreensão e aproveitamento do conhecimento científico é exposto por Almeida (2004), ao afirmar que:

... enquanto os estudantes que não se sentem seguros no uso da linguagem matemática também não se sentirem capazes de aprender física, e os professores dessa disciplina acreditarem que saber matemática é um pré-requisito necessário para qualquer ensino, provavelmente por admitirem como única atividade nobre em aulas de física a resolução de exercícios, a voz dos cientistas terá pouco espaço no ambiente escolar (ALMEIDA, 2004, p. 118).

Nesse contexto, o uso de análogos no ensino de ciências/física apontando para melhor aproveitamento dos estudos pode ser verificado em Almeida (2004), Kemper, Zimmermann e Gastal (2010), Zambon e Terrazzan (2013). Ressaltamos o estudo elaborado por Kemper, Zimmermann e Gastal (2010), que também defende o uso de analogias e metáforas para o letramento científico dos alunos. Silva e Martins (2010) avaliam o uso de analogias para transpor conceitos concretos em abstratos a fim de facilitar o entendimento dos alunos, além de contribuir para um ensino de física mais agradável. O mesmo evidencia-se em Custodio Filho e Oliveira (2000), Gomes-Maluf e Souza (2008), Gomes, Souza e Piassi (2010), Silva e Terrazzan (2009), Terrazzan (1996).

Ainda, sobre o rendimento escolar com o uso de análogos, ressaltamos a promoção de produção de analogias pelos próprios alunos, como apresentado por Zambom e Terrazzan (2013), os autores trabalharam com o conceito físico de energia interna e verificaram que a maioria dos análogos produzidos pelos alunos tem origem concreta. Tal definição se encontra em uma tabela, onde os autores apresentam as categorias das analogias segundo a sua natureza em: interno/externo à estrutura conceitual da física; estruturais, funcionais e estruturais-funcionais; abstrata-abstrata, concreta-abstrata e concreta-concreta. Os resultados demonstram que o uso a produção de analogias por parte dos próprios alunos tem grande potencial para o ensino de física, servindo tanto como estratégia avaliativa, quanto facilitadora de compreensão conceitual e do desenvolvimento do raciocínio analógico dos alunos.

As potencialidades e limitações das analogias e metáforas são exploradas, inclusive no ensino universitário pelos trabalhos de Bozelli e Nardi (2005, 2006), Flôr e Cassiani (2011); Londero e Terrazzan (2005), Otero, Moreira e Greca (2002). Outras contribuições e limitações sobre o uso de analogias são encontradas nos trabalhos de Duarte (2005), Menezes et al. (1994), Silva e Almeida (2008), Silva et al. (2006), Souza, Justi e Ferreira (2006), Terrazzan e Feltrin (2000). 
As analogias e metáforas como recursos de linguagem e facilitadoras de processos discursivos e de interação social e cultural são estudadas e apresentadas por Barja e Redigolo (2005), Bozelli (2005), Bozelli e Nardi (2012), Cunha (2006), Gomes, Souza e Piassi (2010), Laburú e Silva (2011), Piassi e Oliveira (2005), Piassi e Pietrocola (2007), Sasseron (2011), Sapunaru e Tolentino (2015).

Ressaltamos a constatação de Sapunaru e Tolentino (2015) ao verificarem que "para Bachelard, a linguagem imagética e metafórica não poderia e nem deveria ficar reduzida à poesia porque ela pode e deve ser usada para explicar problemas da ordem do conhecimento científico em geral, e da ciência física, em particular" (SAPUNARU; TOLENTINO, 2015).

Assim, os trabalhos em geral acima apresentados apontam para um melhor aprendizado e melhor aproveitamento em avaliações com o uso de analogias, quando comparados com provas tradicionais. Indicam ainda a facilidade que as analogias proporcionam para transpor conceitos concretos em abstratos, a fim de facilitar o entendimento dos alunos, além de contribuir para um ensino de física mais agradável. Permitem também melhor preparo dos professores para lidar com questões de linguagem, procurando deixar claro aos alunos o que são representações, metáforas e analogias usadas na elaboração de modelos e nas explicações de conceitos científicos. Mostram ainda que o raciocínio analógico parece ser a fonte da compreensão dos estudantes com relação ao entendimento dos conceitos teóricos. Nesse sentido as analogias são facilitadoras para a aprendizagem de disciplinas abstratas como a física.

É importante ressaltar que, apesar de existirem divergências teóricas quanto ao uso de analogias, seus benefícios e malefícios não são tratados, nem analisados em nossa revisão bibliográfica com a necessária profundidade, pois não é nosso objetivo de pesquisa. Nosso recorte foi bem estabelecido no sentido de apresentar as possibilidades didáticas dessas ferramentas ao ensino de ciências/física. Uma análise mais profunda não caberia nessa revisão bibliográfica, sendo necessária, sobretudo, uma pesquisa própria a esse respeito. Inclusive, a necessidade dessa investigação e outras, são sugeridas em vários dos textos apresentados em nossa revisão bibliográfica, cabendo a futuras pesquisas analisar essas questões.

Entretanto, apesar de considerável corpus de trabalhos teóricos e empíricos sobre a utilização de analogias no ensino de ciências, como mostra a revisão bibliográfica históricafilosófica de Duarte (2005), pouco impacto real está sendo observado na sala de aula e nos livros didáticos. Paradoxalmente, os autores apresentados concordam quanto à melhoria da aprendizagem em ciências com o uso de analogias, sendo, praticamente consenso em se considerar como proveitoso o uso das analogias por se constituírem como ferramenta de pensamento que possibilita a compreensão de um novo conhecimento através de um conhecimento anterior mais familiar.

Uma possível explicação para esse fenômeno possa ser a lacuna existente nos estudos dessa área quanto a trabalhos com propostas metodológicas que ofereçam material didático, nos 
quais os conteúdos programáticos sejam desenvolvidos paralelamente com análogos conceituais, a fim de que se verifique sua validade quanto à melhoria do aprendizado dos alunos nas aulas de física.

\section{Considerações finais}

Na revisão bibliográfica apresentada pudemos relacionar os estudos que tratassem de leituras, escritos, inserção de textos, interpretações textuais, divulgação científica, ficção científica, do papel e utilização de metáforas e analogias, além de textos históricos e filosóficos da ciência/física, como possíveis de serem pertencentes a um único eixo temático denominado física e literatura, conforme nos possibilitou a interpretação do termo literatura pela Teoria da Literatura de Wellek e Warren (1962). Foram apresentados os trabalhos em três partes principais: as relações entre ciência/física e literatura com a leitura, com a divulgação científica e com o uso de metáforas e analogias.

Torna-se relevante salientar que os vários trabalhos voltados para o papel da leitura no ensino de ciências consideram que trabalhar a leitura em aulas de Física é trabalhar com a ciência na sociedade e na história; é trabalhar a compreensão da própria ciência como produtora de sentidos (ALMEIDA; SILVA; MACHADO, 2001). Mas, esses trabalhos pouco consideram as relações da física com a literatura. Caso seja importante a inserção da leitura, de textos de divulgação/ficção científica, bem como o uso de analogias e metáforas no ensino de física, como mostram os trabalhos apresentados, então porque não se construir uma ponte didática que permita aos estudantes caminharem seguramente entre um texto literário, que contenha esses recursos, e um livro-texto científico? Entende-se, portanto, que há uma lacuna existente nos estudos que tratam da importância da relação entre física e literatura, principalmente sobre estudos teóricos que investiguem e promovam formas de inserir a literatura e seus recursos no ensino de física, constituindo uma fonte promissora para novas investigações.

Outro aspecto importante é o de que a inserção da leitura e de textos não é consolidada como objeto de ensino nos conteúdos de física do EM ou mesmo do Ensino Superior (ES). Os conteúdos de Física Clássica ou Física Moderna e Contemporânea, geralmente, não abordam em seu ensino a introdução de leituras, sejam essas literárias, filosóficas, históricas ou de divulgação científica, nem exploram seus potenciais didáticos da forma como apontam os trabalhos apresentados em nossa revisão bibliográfica, no máximo, encontramos os chamados box com alguma leitura superficial sobre um cientista/físico ou um conceito. Há casos de trabalhos isolados, mas constituem exceções no ensino de física, que não se concretizam, por exemplo, em livros textos a serem utilizados pelos professores em sala de aula. $\mathrm{O}$ mesmo se aplica aos livros de ES.

Em geral, os estudos apresentados vêm apontando para uma aproximação, com indicações para a existência de uma melhor compreensão conceitual pelos alunos que leram textos científicos, apresentando, inclusive, melhores resultados, quando comparados com alunos que seguiram um ensino tradicional, sem leitura alguma (NIGRO; TRIVELATO, 2010). Apontam 
também para o aumento da curiosidade e do prazer, ao se trabalhar esses conceitos pelo viés da leitura e não pelo formalismo matemático tradicional, desempenhando um papel desencadeador de motivação no leitor, pois sua linguagem é mais acessível, possibilitando um gosto maior por parte dos alunos no estudo da física (MONTEIRO; GASPAR; MONTEIRO, 2005).

As relações e os apontamentos obtidos dos trabalhos analisados em nossa revisão bibliográfica são bem claros: deve-se levar a leitura para o ensino de ciências. Isso traz significado e facilita a compreensão dos alunos em relação aos conceitos físicos, permitindo melhor entendimento a respeito dos fenômenos que estudam. A grande maioria dos trabalhos identificaram, inclusive, o termo prazer em se estudar a física, aumentando a empatia por parte dos alunos, o que, claramente, facilita o trabalho do professor, subsidiando-o na construção do conhecimento científico que pretende ensinar, uma vez que os recursos literários utilizados já fomentaram a curiosidade dos alunos.

Os poucos trabalhos que apontaram alguma crítica sobre o ensino de física articulado com a literatura, seja essa entendida como leitura, divulgação/ficção científica ou por meio do uso de metáforas e analogias, ressaltam a interpretação errônea de conceitos científicos ou, um reforço das concepções alternativas (VIENNOT, 1977) dos alunos, contudo, essas críticas não sobrevivem a uma análise mais profunda, pois não há garantias de que o aluno vá abandonar seus conhecimentos prévios (BACHELARD, 1996), ao assistir, por exemplo, uma aula de cinemática via exposição das funções horárias do movimento retilíneo uniforme e uniformemente variado, seguidos de uma lista de 10 ou mais exercícios. Essas críticas não respondem alguns problemas centrais: Como o aluno aprende um conceito científico? Como ensinar um conceito científico de forma que o aluno o aprenda imediatamente e abandone suas concepções alternativas, seus conhecimentos prévios adquiridos ao longo de sua formação e seu senso comum, construídas histórica e socialmente em seu meio familiar, social e escolar? Certamente que a repetição de exercícios de fixação não é a solução, caso contrário os problemas em ensino de física estariam resolvidos há décadas.

Nesse contexto, Viennot (1977) já havia sinalizado que não se compreende a forma como o aluno aprende conceitos científicos. Sua percepção é atual. E eventuais preocupações quanto à aquisição de concepções errôneas ou o seu reforço se devem à falta da compreensão da evolução dos processos de construção dos conceitos científicos pelos alunos. Assim, identificamos, pelos trabalhos apresentados, que a utilização da literatura e seus recursos possibilitam um contato mais próximo das concepções dos alunos, constituindo mais benefícios que malefícios em seu uso, pois subsidiam as ações do professor na construção dos conceitos científicos pretendidos com seus alunos.

Possibilidades de se trabalhar com essas concepções devem ser vinculadas à importância da mediação do professor, seu papel é primordial para identificar o tipo de leitura, o tipo de análogo ou texto a ser trabalhado com seus alunos. Para tanto, como apontam vários trabalhos apresentados em nossa revisão bibliográfica é preciso, também, investir na inserção de leituras, inclusive com o papel de analogias, na formação inicial e continuada dos professores. 
Esperamos, por fim, termos contribuído para que futuros pesquisadores possam encontrar subsídios nessa revisão bibliográfica ao investigarem as relações entre física e literatura. Futuras pesquisas podem contribuir em responder sobre a real ligação entre o ensino e aprendizagem que a literatura possa proporcionar ao ensino de ciências/física, ressaltando-se a escassez de trabalhos que investiguem a fundo as relações existentes entre a física e a literatura. $\mathrm{O}$ que parece faltar é mostrar qual é o amalgama que garante essa aproximação.

Torna-se necessário investigar o que realmente acontece com o estudante, quando ele é aproximado da literatura, da leitura de textos, sejam elas, literaturas científicas, históricas, filosóficas, ou de divulgação científica, e de que forma o estudante irá relacionar essa leitura com os conceitos físicos, beneficiando-o em seu aprendizado. Uma possível forma de se preencher essa lacuna pode encontrar respaldos teóricos nos estudos de Vygotsky (2008) a respeito da importância da palavra, e do desenvolvimento da abstração por meio da leitura, como, também é apontado por Lima (2014), onde o papel da literatura e leitura é estudado como potencial formador da abstração de conceitos físicos, possibilitando ao estudante um melhor aprendizado dos conceitos científicos estudados, complementando o formalismo matemático e dando sentido a este.

\section{Bibliografia}

ADORNO, T.W.; HORKHEIMER, M. Dialética do esclarecimento. Rio de Janeiro: Editora Jorge Zahar, 1985. 224 p.

ALEXANDER, P.A; KULIKOWICH, J. M. Learning from physics text: a synthesis of recent research. Journal of Research in Science Teaching, v. 31, n. 9, p. 895-911, 1994.

ALMEIDA, M. J. P. Discursos da Ciência e da Escola: ideologia e leituras possíveis. 1. ed. Campinas: Mercado de Letras, 2004. v. 1. 120 p.

ALMEIDA, M. J. P. M. O texto escrito na educação em física: enfoque na divulgação científica. In: ALMEIDA, M. J. P. M.; SILVA, H. C. da (Orgs.). Linguagens, leituras e ensino da ciência. Campinas: Mercado de Letras: Associação de Leitura do Brasil, 1998. p. 53-68.

ALMEIDA, M. J. P. M.; QUEIROZ, E. C. L. Divulgação científica e conhecimento escolar: um ensaio com alunos adultos. Cadernos do CEDES (UNICAMP), Campinas, v. 41, p. 62-68, 1997.

ALMEIDA, M. J. P. M.; RICON, A. E. Divulgação Científica e Texto Literário: uma perspectiva cultural em aulas de Física. Caderno Catarinense de Ensino de Física, Florianópolis, v. 10, n.1, p. 7-13, 1993. 
ALMEIDA, M. J. P. M.; SILVA, H. C.; MACHADO, J. L. M. Condições de produção no funcionamento da leitura na educação em física. Revista Brasileira de Pesquisa em Educação em Ciências, v. 1, n. 1, Janeiro/Abril, p 5-18, 2001.

ANDRADE, I. B.; MARTINS, I. Discursos de professores de ciências sobre leitura. Revista Investigações em Ensino de Ciências, v. 11, n. 2, p. 121-151, 2006.

BACHELARD, G. A formação do Espírito Científico. Trad. Estela dos Santos Abreu. Rio de Janeiro: Editora Contraponto, 1996. 316 p.

BAKER, D. R. A sumary of research in science education - 1989: textbooks and text comprehension. Science Education, 75 n. 3, p. 359-367, 1991.

BAKER, L.; S. W. Considering science and language arts connections: a study of teacher cognition. Journal of Research in Science Teaching, v. 31, n. 9, p. 1023-1037, 1994.

BARBOSA-LIMA, M. C.; CARVALHO, A. M. P. Linguagem e o ensino de física na escola fundamental. Caderno Brasileiro de Ensino de Física, v. 20, n. 1, p. 86-97, abr. 2003.

BARCELLOS, M. E. Inserindo a física moderna no ensino médio através da leitura: uma abordagem quântica da condução elétrica em cristais de cobre. In: SIMPÓSIO NACIONAL DE ENSINO DE FÍSICA, XVI, 2005, Rio de Janeiro. Anais... Rio de Janeiro: SBF, CEFET, 2005.

BARJA, P. R.; REDÍGOLO, M. L. Homem-Aranha e o Ensino de Física. In: SIMPÓSIO NACIONAL DE ENSINO DE FÍSICA, XVI, 2005, Rio de Janeiro. Anais... Rio de Janeiro: SBF, CEFET, 2005.

BONAGAMBA, T. J.; CAPELLE, K. W.; AZEVEDO, E. R. A RMN e suas aplicações atuais. Ciência Hoje, v. 37, n. 221, p. 40-48, 2005.

BOZELLI, F. C.; NARDI, R. Interações discursivas e o uso de analogias no ensino de física. Revista Investigações em Ensino de Ciências, v. 17, n. 1, p. 81-107, 2012.

BOZELLI, F. C.; NARDI, R. O uso de analogias e metáforas em aulas de física no ensino superior: algumas considerações. In: ENCONTRO NACIONAL DE PESQUISA EM EDUCAÇÃO EM CIÊNCIAS, V, 2005. Bauru. Anais... São Paulo: ABRAPEC, 2005.

BOZELLI, F.; NARDI, R. O uso de analogias no ensino de física em nível universitário: interpretações sobre os discursos do professor e dos alunos. Revista Brasileira de Pesquisa em Educação em Ciências, v. 6, n. 3, 2006.

BOZELLI, F. C. Analogias e metáforas no ensino de Física: o discurso do professor e o discurso do aluno. 2005. Dissertação (Mestrado em Educação para a Ciência) - Faculdade de Ciências, Bauru. 
BRICCIA, V.; CARVALHO, A. M. P. Visões sobre a natureza da ciência construídas a partir do uso de um texto histórico na escola média. Revista Electrónica de Enseñanza de las Ciencias, v. 10, n. 1, p. 1-22, 2011.

BRITO, N, B.; REIS, J. C. Relações entre a Física e a Arte: uma perspectiva artística na construção do conceito físico de cor. In: SIMPÓSIO NACIONAL DE ENSINO DE FÍSICA, XXI, 2015, Uberlândia. Anais... Minas Gerais: SBF, 2015.

BROWN, D. E. Refocusing core intuitions: a concretizing role for analogy in conceptual change. Journal of Research in Science Teaching, v. 30, n.10, p. 1273-1290, 1993.

CAMPOS, A.; RICARDO, E. C. A natureza da região celeste em Aristóteles. Revista Brasileira de Ensino de Física, v. 36, n. 4, p. 4601, 2014.

CARVALHO, S. H. M.; ZANETIC, J. Ciência e arte, razão e imaginação: complementos necessários à compreensão da física moderna. In: ENCONTRO DE PESQUISA EM ENSINO DE FÍSICA, IX, 2004, Jaboticatubas. Anais... Minas Gerais: SBF, 2004.

CARVALHO, S. H. M.; ZANETIC, J. Ciência e arte, razão e imaginação: um projeto de ensino de física moderna para alunos do ensino médio. In: SIMPÓSIO NACIONAL DE ENSINO DE FÍSICA, XVI, 2005, Rio de Janeiro. Anais... Rio de Janeiro: SBF, CEFET, 2005.

CHASSOT, A. Alfabetização científica: questões e desafios para a educação. 3. ed. Ijuí: Unijuí, 2003.

CHAVES, T. V.; MEZZOMO, J.; TERRAZZAN E. A. Avaliando práticas didáticas de utilização de textos de divulgação científica como recurso didático em aulas de física no ensino médio. In: ENCONTRO NACIONAL DE PESQUISA EM EDUCAÇÃO EM CIÊNCIAS, III, 2001, Atibaia. Anais... São Paulo: ABRAPEC, 2001.

CLEMENTE, J. Using bridging analogies and anchoring intuitions to deal with students' preconceptions in physics. Journal of Research in Science Teaching, v. 30, n.10, p. 1241-1257, 1993.

COUTINHO, A. Notas de teoria literária. 2. ed. Rio de Janeiro: Civilização Brasileira, 1978.

CUNHA, M. Analogias nos livros de ciências para as séries iniciais do ensino fundamental. Revista Brasileira de Pesquisa em Educação em Ciências, v. 6, n. 2, 2006.

CUSTÓDIO FILHO, J. F.; OLIVEIRA, M. P. Princípios físicos e a construção de modelos. In: ENCONTRO DE PESQUISA EM ENSINO DE FÍSICA, VII, 2000, Florianópolis. Anais... Santa Catarina: SBF, 2000. 
CUSTÓDIO PINTO, A.; ZANETIC, J. Contribuições das filosofias da ciência para uma reflexão sobre as (re)concepções do ensino de física. In: ENCONTRO DE PESQUISA EM ENSINO DE FÍSICA, VII, 2000, Florianópolis. Anais... Santa Catarina: SBF, 2000.

DECIAN, E.; CORREIA, D.; SAUERWEIN, I. P. S. Atividades de leitura e escrita nas aulas de Física: a contribuição dos textos de divulgação científica. In: SIMPÓSIO NACIONAL DE ENSINO DE FÍSICA, XXI, 2015, Uberlândia. Anais... Minas Gerais: SBF, 2015.

DIAS, R. H. A.; ALMEIDA, M. J. P. M. de. Especificidades do jornalismo científico na leitura de textos de divulgação científica por estudantes de licenciatura em física. Revista Brasileira de Ensino de Física, São Paulo, v. 31, n. 4, 2009.

DUARTE, M. C. Analogias na educação em ciências contributos e desafios. Revista Investigações em Ensino de Ciências, v. 10, n. 1, p. 7-29, 2005.

DUARTE, M. C. Analogias na educação em ciências contributos e desafios. Revista Investigações em Ensino de Ciências, v. 10, n. 1, p. 7-29, 2005.

FELLOWS, N. J. A window into thinking: using student writing to understand conceptual change in science learning. Journal of Research in Science Teaching, v. 31, n. 9, p. 985-1001, 1994.

FERRAZ, A. S. D.; DUARTE, J. S.; CUNHA, F. M.; BERTOLLI FILHO, C.; ARRUDA, M. S. P. Leitura e compreensão de textos nos livros didáticos de ciências: um problema no significado das palavras. In: ENCONTRO NACIONAL DE PESQUISA EM EDUCAÇÃO EM CIÊNCIAS, III, 2001, Atibaia. Anais... São Paulo: ABRAPEC, 2001.

FERRAZ, D. F.; TERRAZZAN, E. A. O uso de analogias como recurso didático por professores de Biologia no Ensino Médio. Revista Brasileira de Pesquisa em Educação em Ciências, v. 1, n. 3, p. 124-135, 2001.

FERRAZ, D. F.; TERRAZZAN, E. A. Uso espontâneo de analogias por professores de Biologia e uso sistematizado de analogias: que relação? Ciência \& Educação, Bauru, v. 9, n. 2, p. 213 227, 2003.

FERRAZ, D. F.; TERRAZZAN, E. A. Construção do conhecimento e Ensino de Ciências: papel do raciocínio analógico. Educação, 2002.

FLÔR, C. C.; CASSIANI, S. O que dizem os estudos da linguagem na educação científica? Revista Brasileira de Pesquisa em Educação em Ciências, v. 11 n. 2, 2011.

FONSECA, L. S.; ANDRADE, L. A. M.; SILVA, R. R. A literatura como ferramenta didáticopedagógica no ensino de Física. In: SIMPÓSIO NACIONAL DE ENSINO DE FÍSICA, XXI, 2015, Uberlândia. Anais... Minas Gerais: SBF, 2015. 
FRANCISCO JUNIOR, W. E. Aprendendo sobre o funcionamento da ciência a partir da leitura em sala de aula. In: ENCONTRO NACIONAL DE PESQUISA EM EDUCAÇÃO EM CIÊNCIAS, VII, 2009. Florianópolis. Anais... Santa Catarina: ABRAPEC, 2009.

GASKINS, I. W.; GUTHRIE, J. T.; SATLOW, E.; OSTERTAG, J.; SIX, L.; BYRNE, J.; CONNOR, B. Integrating instruction of science, reading, and writing: goals, teacher development, and assessment. Journal of Research in Science Teaching, v. 31, n. 9, p. 1039-1056, 1994.

GILMORE, R. Alice no País do Quantum. Rio de Janeiro: Editora Jorge Zahar, 1998, 192 p. Disponível em:

<http://moodle.stoa.usp.br/file.php/1294/Material_Complementar/AL-

ICE_NO_PAIS_DO_QUANTUM_-_A_FISICA_QUANTICA_AO_ALCANCE_DE_TODOS_-_ROBERT_GILMORE.pdf>. Acesso em: 22 dez. 2014.

GIRALDELLI, C. G. C. M.; ALMEIDA, M. J. P. M. Leitura coletiva de um texto de literatura infantil no Ensino Fundamental: algumas mediações pensando o ensino das ciências. Ensaio. Pesquisa em Educação em Ciências, v. 10, p. 1-19, 2008.

GLYNN, S. M.; LAW, M.; GIBSON, N. M; HAWKINS, C. H. Teaching science with analogies: a resource for teachers and texbooks authors. 1998. Disponível em: <http://curry.virginia.edu/go/clic/nrrc/scin_ir7.html>. Acesso em: 24 dez. 2014.

GLYNN, S. M.; MUTH, K. D. Reading and writing to learn science: Achieving scientific literacy. Journal of Research in Science Teaching, v. 31, n. 9, p. 1057-1073, 1994.

GOMES, E. F.; SOUZA, R. M.; PIASSI, L. P. C. O romance de ficção científica e o ensino de física: mediação sob o olhar da filosofia da diferença. In: ENCONTRO DE PESQUISA EM ENSINO DE FÍSICA, XII, 2010, Águas de Lindóia. Anais... São Paulo: SBF, 2010.

GOMES-MALUF, M. C.; SOUZA, A. R. A ficção científica e o ensino de ciências: o imaginário como formador do real e do racional. Ciência \& Educação, Bauru, SP, v. 14, n. 2, p. 271 282, 2008.

GUERRA, A.; MENEZES, A. M. S. Literatura na física: uma possível abordagem para o ensino de ciências? In: ENCONTRO NACIONAL DE PESQUISA EM EDUCAÇÃO EM CIÊNCIAS, VII, 2009, Florianópolis. Anais... Santa Catarina: ABRAPEC, 2009.

GUERRA, A.; MENEZES, A. M. Literature in Physics: a possible approach to science education. In: IOSTE, XIV, 2010, Bled, Eslovênia. Socio-cultural and Human Values in Science and Technology Education. Anais... Ljubljana: IRI UL, Institute for Innovation and Development of University of Ljubljana, 2010. 
GUERRA, A.; BRAGA, M.; REIS, J. C. Diálogos Interdisciplinares no Ensino de Física: Relações entre Física e Pintura. In: SIMPÓSIO NACIONAL DE ENSINO DE FÍSICA, XV, 2003, Curitiba. Anais... Paraná: SBF, 2003.

GURGEL, I.; PIETROCOLA, M. O papel da imaginação no pensamento científico: análise da criação científica de estudantes em uma atividade didática sobre o espalhamento de Rutherford. Caderno Brasileiro de Ensino de Física, v. 28, n. 1, p. 91-122, abr. 2011.

GURGEL, I; PIETROCOLA, M. Uma discussão epistemológica sobre a imaginação científica: a construção do conhecimento através da visão de Albert Einstein. Revista Brasileira de Ensino de Física, v. 33, n. 1, 2011.

HARRISON, A. G.; TREAGUST, D. F. Science analogies. The Science Teacher, v. 61, p. 4043, 1994.

HARRISON, A. G.; TREAGUST, D. F. Teaching with analogies: A case study in grade-10 optics. Journal of Research in Science Teaching, v. 30, p. 1291-1307, 1993.

HOLLIDAY, G. W.; YORE, L. D.; ALVERMANN, D. E. The reading - science learning writing connection: Breakthroughs, barriers, and promises. Journal of Research in Science Teaching, v. 31, n. 9, p. 877-893, 1994.

HYND, C. R.; MCWHORTER, J. Y.; PHARES, V. L.; SUTTLES, C. W. The role of instructional variables in conceptual change in high school physics topics. Journal of Research in Science Teaching, v. 31, n. 9, p. 933-946, 1994.

KEMPER, A.; ZIMMERMANN, E.; GASTAL, M. L. Textos populares de divulgação científica como ferramenta didático-pedagógica: o caso da evolução biológica. Revista Brasileira de Pesquisa em Educação em Ciências, v. 10, n. 3, 2010.

KEYS, C. W. The development of scientific reasoning skills in conjunction with collaborative writing assignments: An interpretive study of six ninth-grade students. Journal of Research in Science Teaching, v. 31, n. 9, p. 1003-1022, 1994.

KINOUCHI, O.; KINOUCHI J. M.; MANDRÁ, A. A. Metáforas científicas no discurso jornalístico. Revista Brasileira de Ensino de Física, v. 34, n. 4, 2012.

LABURÚ, C. E.; SILVA, O. H. M. Multimodos e múltiplas representações: Fundamentos e perspectivas semióticas para a aprendizagem de conceitos científicos. Revista Investigações em Ensino de Ciências, v. 16, n. 1, p. 7-33, 2011.

LAKOFF, G.; JOHNSON, M. Metaphors We Live By. Chicago: University of Chicago, 1980.

LAKOFF, G.; NÚÑEZ, R. Where Mathematics comes from. New York: Basic Books, 2000. 
LAWSON, A. E. The importance of analogy: A prelude to the special issue. Journal of Research in Science Teaching, v. 30, n. 10, p. 1213-1214, 1993.

LAWSON, D. I.; LAWSON, A. E. Neural principles of memory and a neural theory of analogical insight. Journal of Research in Science Teaching, v. 30, n. 10, p. 1327-1348, 1993.

LIMA, L. G. A abstração como ponte entre a física e a literatura na construção de conceitos de Mecânica Quântica no Ensino Médio. 2014. Dissertação (Mestrado) - Universidade de São Paulo, Programa Interunidades em Ensino de Ciências. São Paulo.

LIMA, L. G. O estudo do Movimento Retilíneo Uniforme dos corpos através da leitura de trechos da $2^{\mathrm{a}}$ Jornada do livro Diálogo Sobre os Dois Máximos Sistemas do Mundo Ptolomaico e Copernicano, de Galileu Galilei. Revista Física na Escola, v. 13, n. 1, 2012.

LIMA, L. G.; RICARDO, E. C. A literatura como ferramenta didática no ensino de Mecânica Quântica para o Ensino Médio. In: SIMPÓSIO NACIONAL DE ENSINO DE FÍSICA, XXI, 2015, Uberlândia. Anais... Minas Gerais: SBF, 2015.

LIMA, M. C. B. Explique o que tem nessa história. 2000. Tese (Doutorado em Educação) Faculdade de Educação, USP, São Paulo.

LIMA, M. C. B.; BARROS, H. L.; TERRAZZAN, E. A. Quando o sujeito se torna pessoa: uma articulação possível entre Poesia e ensino de Física. Ciência \& Educação, Bauru, v. 10, n. 2, 2004.

LONDERO, L. S.; TERRAZZAN, E. A. As analogias no ensino de conteúdos conceituais de física. In: ENCONTRO NACIONAL DE PESQUISA EM EDUCAÇÃO EM CIÊNCIAS, V, n. 5, 2005, Bauru. Anais... São Paulo: ABRAPEC, 2005.

LOPES, E. M.; SALOMÃO, S. R. O uso da literatura no ensino de ciências no primeiro segmento do ensino fundamental: desafios e possibilidades. In: ENCONTRO NACIONAL DE PESQUISA EM EDUCAÇÃO EM CIÊNCIAS, VII, 2009, Florianópolis. Anais... Santa Catarina: ABRAPEC, 2009.

MACHI, F.; LEITE, C. A leitura no ensino de física no cenário dos periódicos nacionais. In: ENCONTRO DE PESQUISA EM ENSINO DE FÍSICA, XII, 2010, Águas de Lindóia. Anais... São Paulo: SBF, 2010.

MECKE, K. R. A Imagem da literatura na Física. Gazeta de Física, nov. 2004. Disponível em: <http://www.theorie1.physik.uni-erlangen.de/mecke/publ.html>. Acesso em: 25 dez. 2014.

MENEZES, A. M.; GUERRA, A. Física e Literatura: intersecções possíveis em sala de aula. In: SIMPÓSIO NACIONAL DE ENSINO DE FÍSICA, XVIII, 2009, Vitória. Anais... Espírito Santo: SBF, 2009. 
MENEZES, L. C. A matéria, uma aventura do espírito. São Paulo: Livraria da Física, 2005.

MENEZES, L. C.; KAWAMURA, R. D.; HOSOUME, Y. Objetos e objetivos no aprendizado da Física. In: ENCONTRO DE PESQUISA EM ENSINO DE FÍSICA, IV, 1994, Florianópolis. Anais... Santa Catarina: SBF-UFSC, 1994.

MOEBUS, R.; MARTINS, I. Leitura e alfabetização científica nas aulas de ciências: uma revisão de artigos publicados entre 2008 e 2012. In: ENCONTRO NACIONAL DE PESQUISA EM EDUCAÇÃO EM CIÊNCIAS, IX, 2013, Águas de Lindóia. Anais... São Paulo: ABRAPEC, 2013.

MONTEIRO, I. C. C.; GASPAR, A.; MONTEIRO, M. A. A. A motivação dos alunos num contexto de leitura de texto de divulgação científica. In: SIMPÓSIO NACIONAL DE ENSINO DE FÍSICA, XVI, 2005, Rio de Janeiro. Anais... Rio de Janeiro: SBF, CEFET, 2005.

MOURÃO, R. R. F. A importância da leitura na vocação técnico-científica: o caso especial dos pioneiros da astronáutica. In: SIMPÓSIO INTERNACIONAL TRANSDISCIPLINAR DE LEITURA, 2000, Rio de Janeiro. Anais...

NASCIMENTO, C.; BARBOSA-LIMA, M. C. O ensino de física nas séries iniciais do ensino fundamental: lendo e escrevendo histórias. Revista Brasileira de Pesquisa em Educação em Ciências, v. 6, n. 3, 2006.

NASCIMENTO, T. G.; REZENDE JUNIOR, M. F. A produção sobre divulgação científica na área de educação em ciências: referenciais teóricos e principais temáticas. Revista Investigações em Ensino de Ciências, v. 15, n. 1, p. 97-120, 2010.

NETO, P. C. P. Júlio Verne: o propagandista das ciências. Revista Ciência e Ensino, n. 12, Campinas, 2004.

NIGRO, R. G.; TRIVELATO, S. L. F. Leitura de textos de ciências de diferentes gêneros: um olhar cognitivo-processual. Revista Investigações em Ensino de Ciências, v. 15, n. 3, p. 553$573,2010$.

NORRIS, S. P.; GUILBERT, S. M.; PHILIPS, L. M.; SHAHRAM, H.; SMITH, M. L. A theoretical framework for narrative explanation in science. Science Education, v. 89, n. 4, p. 535$563,2005$.

NORRIS, S. P.; PHILLIPS, L. M. Interpreting pragmatic meaning when reading popular reports of science. Journal of Research in Science Teaching, v. 31, n. 9, p. 947-967, 1994.

NORY, R. M.; ZANETIC, J. O teatro e a física: a cena que não entra em sala. In: SIMPÓSIO NACIONAL DE ENSINO DE FÍSICA, XVI, 2005, Rio de Janeiro. Anais... Rio de Janeiro: SBF, CEFET, 2005. 
NUNES, R. R.; FERRAZ, D. F.; JUSTIN, L. A. D. Estudos relativos a analogias no ensino de Ciências. In: ENCONTRO NACIONAL DE PESQUISA EM EDUCAÇÃO EM CIÊNCIAS, VI, 2007, Florianópolis. Anais... Santa Catarina: ABRAPEC, 2007.

OLIVEIRA, L. M. Estabelecendo o diálogo entre as duas culturas: imaginação e criatividade aliadas ao ensino de Física. In: SIMPÓSIO NACIONAL DE ENSINO DE FÍSICA, XXI, 2015, Uberlândia. Anais... Minas Gerais: SBF, 2015.

ORLANDI, E. P. Análise de discurso: princípios e procedimentos. Campinas: Pontes Editores, 1999. 100p.

OTERO, M. R.; MOREIRA, M. A.; GRECA, M. I. El uso de imágenes en textos de física para la enseñanza secundaria y universitaria. Revista Investigações em Ensino de Ciências, v. 7, n. 2, p. 127-154, 2002.

PADILHA, J. N.; CARVALHO, A. M. P. Relações entre os gestos e as palavras utilizadas durante a argumentação dos alunos em uma aula de conhecimento físico. Revista Brasileira de Pesquisa em Educação em Ciências, v. 11, n. 2, 2011.

PAULA, H. F.; BORGENS, A. T. A compreensão dos estudantes sobre o papel da imaginação na produção das ciências. Caderno Brasileiro de Ensino de Física, v. 25, n. 3, p. 478-506, dez. 2008.

PAULA, H. F.; LIMA, M. E. C. C. L. Formulação de questões e mediação da leitura. Revista Investigações em Ensino de Ciências, v. 15, n. 3, p. 429-461, 2010.

PÊCHEUX, M. O discurso: estrutura ou acontecimento. Campinas: Pontes Editores, 1990.

PEREIRA, A. G.; TERRAZZAN, E. A. A multimodalidade em textos de popularização científica: contribuições para o ensino de ciências para crianças. Ciência \& Educação, v. 17, p. 489$503,2011$.

PEREIRA, J. M.; LONDERO, L. O ensino de partículas elementares por meio da leitura de "Alice no País do Quantum". In: SIMPÓSIO NACIONAL DE ENSINO DE FÍSICA, XX, 2013, São Paulo. Anais... São Paulo: SBF, USP, 2013.

PESSOA JÚNIOR, O. Quando a abordagem histórica deve ser usada no Ensino de Ciências? Revista Ciência e Ensino, v.1, 1996.

PESSOA JÚNIOR, O. Conceitos de Física Quântica. São Paulo: Livraria da Física, 2003.

PIASSI, L. P. C. A perspectiva sociocultural da física nos romances de ficção científica de Arthur Clarke. Revista Brasileira de Pesquisa em Educação em Ciências, v. 11, n. 2, 2011. 
PIASSI, L. P.; OLIVEIRA, M. P. P. Ficção científica no ensino de física: utilizando um romance para desenvolver conceitos. In: SIMPÓSIO NACIONAL DE ENSINO DE FÍSICA, XVI, 2005, Rio de Janeiro. Anais... Rio de Janeiro: SBF, CEFET, 2005.

PIASSI, L. P.; PIETROCOLA, M. Quem conta um conto aumenta um ponto também em física: contos de ficção científica na sala de aula. In: SIMPÓSIO NACIONAL DE ENSINO DE FÍSICA, XVII, 2007, São Luís. Anais... Maranhão: SBF, 2007.

PINTO, A. A.; RABONI, P. C. A. Concepções de ciência na literatura brasileira: conhecer para explorar possibilidades. In: ENCONTRO NACIONAL DE PESQUISA EM EDUCAÇÃO EM CIÊNCIAS, V, 2005, Bauru. Anais... São Paulo: ABRAPEC, 2005.

PUIATI, L. L.; BOROWSKI, H. G.; TERRAZZAN, E. A. O texto de divulgação científica como recurso para o ensino de ciências na educação básica: um levantamento das produções nos ENPEC. In: ENCONTRO NACIONAL DE PESQUISA EM EDUCAÇÃO EM CIÊNCIAS, VI, 2007, Florianópolis. Anais... Santa Catarina: ABRAPEC, 2007, p. 1-10.

RAMOS, J. E. F.; PIASSI, L. P. Humor, ciência, literatura e tudo mais: o guia dos mochileiros das galáxias no ensino de Ciências. In: ENCONTRO NACIONAL DE PESQUISA EM EDUCAÇÃO EM CIÊNCIAS, IX, 2013, Águas de Lindóia. Anais... São Paulo: ABRAPEC, 2013.

REZENDE, F.; OSTERMANN F.; FERRAZ, G. Ensino-aprendizagem de física no nível médio: o estado da arte da produção acadêmica no século XXI. Revista Brasileira de Ensino de Física, v. 31, n. 1, 2009.

RICON, A. E.; ALMEIDA, M. J. P. M. Ensino da Física e Leitura. Leitura: Teoria \& Prática, Campinas, v. 10, n.18, p. 7-16, 1991.

RIVARD, L. O. P. A review of writing to learn in science: implications for practice and research. Journal of Research in Science Teaching, v. 31, n. 9, p. 969-983, 1994.

SAPUNARU, R. A.; TOLENTINO, M. M. A. Sobre o "Bem Entender" do Espírito Científico: o uso das Metáforas e Imagens nas Ciências Físicas. In: SIMPÓSIO NACIONAL DE ENSINO DE FÍSICA, XXI, 2015, Uberlândia. Anais... Minas Gerais: SBF, 2015.

SASSERON, L. H.; CARVALHO, A. M. P. Alfabetização científica: uma revisão bibliográfica. Revista Investigações em Ensino de Ciências, v. 16, n. 1, p. 59-77, 2011.

SCHIFFER, H.; GUERRA, A. a utilização de narrativas históricas na construção do conceito de energia: um estudo de caso. In: ENCONTRO NACIONAL DE PESQUISA EM EDUCAÇÃO EM CIÊNCIAS, VIII, 2011, Campinas. Anais... São Paulo: ABRAPEC, 2011.

SCHWARTZ, D. The construction and analogical transfer of symbolic visualizations. Journal of Research in Science Teaching, v. 30, n. 10, p. 1309-1325, 1993. 
SILVA, A. C.; ALMEIDA, M. J. P. M. Uma leitura de divulgação científica sobre ressonância magnética no ensino médio. In: ENCONTRO NACIONAL DE PESQUISA EM EDUCAÇÃO EM CIÊNCIAS, IX, 2013, Águas de Lindóia. Anais... São Paulo: ABRAPEC, 2013.

SILVA, A. C.; ALMEIDA, M. J. P. M. A leitura por alunos do ensino médio de um texto considerado de alto grau de dificuldade. Alexandria, v. 7, p. 49-73, 2014.

SILVA, C. A.; MARTINS, M. I. Analogias e metáforas nos livros didáticos de física. Caderno Brasileiro de Ensino de Física, v. 27, n. 2, p. 255-287, ago. 2010.

SILVA, H. C. da; ZIMMERMANN, E; CARNEIRO, M. H. S; GASTAL, M. L.; CASSIANO, W. S. Cautela ao usar imagens em aulas de ciências. Ciência \& Educação, Bauru, v. 12, n. 2, 2006.

SILVA, H. C.; ALMEIDA, M. J. P. M. O deslocamento de aspectos do funcionamento do discurso pedagógico pela leitura de textos de divulgação científica em aulas de Física. Revista Electrónica de Enseñanza de las Ciencias, Barcelona, v. 4, n. 3, p. 1-25, 2005.

SILVA, I. M. N. S.; MACIEL, A. M. M.; CARVALHO, G. R.; ALVES, R. L.; XAVIER, A. B.; SANTOS, R. F.; SILVA, S. P. M.; SILVA, P. A. M. O uso de texto de divulgação científica no ensino de física com duas estratégias. In: SIMPÓSIO NACIONAL DE ENSINO DE FÍSICA, XXI, 2015, Uberlândia. Anais... Minas Gerais: SBF, 2015.

SILVA, L. L.; ALMEIDA, M. J. P. M. Linguagem analógica: prós e contras na literatura sobre ensino de física no Brasil. In: ENCONTRO DE PESQUISA EM ENSINO DE FÍSICA, XI, 2008, Curitiba. Anais... Paraná: SBF, 2008.

SILVA, L. L.; PIMENTEL, N. L.; TERRAZZAN, E. A. As analogias na revista de divulgação científica Ciência Hoje das Crianças. Ciência e Educação, v. 17, p. 163-181, 2011.

SILVA, L. L.; TERRAZZAN, E. A. Familiaridade de alunos de ensino médio com situações análogas. Caderno Brasileiro de Ensino de Física, v. 26, n. 1, p. 145-172, abr. 2009.

SILVA, L. L.; TERRAZZAN, E. A. As analogias no ensino de conteúdos conceituais, procedimentais e atitudinais em aulas de Física do Ensino Médio. Experiências em Ensino de Ciências, v. 6, p. 133-154, 2011.

SILVA, L. L.; TERRAZZAN, E. A. As analogias no ensino de conteúdos conceituais de Física. In: ENCONTRO NACIONAL DE PESQUISA EM EDUCAÇÃO EM CIÊNCIAS, V, 2005, Bauru. Anais... São Paulo: ABRAPEC, 2005, p. 1-15.

SILVEIRA, M. P. O potencial de relações entre ensino de ciências e literatura por meio da obra de Monteiro Lobato. In: $1^{\circ}$ CIELLI/4 CELLI, 2010, Maringá-PR. Anais... 
SNOW, C. P. As duas culturas e uma segunda leitura: uma versão ampliada das duas culturas e a revolução científica. São Paulo: Editora da Universidade de São Paulo, 1995.

SOUZA, R. R.; SOUZA, P. H. Textos com erros conceituais e o ensino de física. In: ENCONTRO NACIONAL DE PESQUISA EM EDUCAÇÃO EM CIÊNCIAS, V, 2005. Bauru. Anais... São Paulo: ABRAPEC, 2005.

SOUZA, V. C. A.; JUSTI, R. S.; FERREIRA, P. F. M. Analogias utilizadas no ensino dos modelos atômicos de Thompson e Bohr: Uma análise crítica sobre o que os alunos pensam a partir delas. Revista Investigações em Ensino de Ciências, v. 11, n. 1, p. 7-28, 2006.

SPIEGEL JUNIOR, G. F.; BARUFALDI, J. P. The effects of a combination of text structure awareness and graphic postorganizers on recall and retention of science knowledge. Journal of Research in Science Teaching, v. 31, n. 9, p. 913-932, 1994.

STAVY, R.; TIROSH, D. When analogy is perceived as such. Journal of Research in Science Teaching, v. 30, n.10, p. 1229-1239, 1993.

STRACK, R.; LOGUÉRCIO, R.; DEL PINO , J. C. Percepções de professores de ensino superior sobre a literatura de divulgação científica. Ciência \& Educação, Bauru, v. 15, n. 2, p. 425 42, 2009.

SUTTON, C. Figuring out a scientific understanding. Journal of Research in Science Teaching, v. 30, n. 10, p. 1215-1227, 1993.

TERRAZZAN, E. A. Analogias e metáforas no ensino de ciências naturais. In: ENCONTRO DE PESQUISA EM ENSINO DE FÍSICA, V, 1996, Águas de Lindóia. Anais... São Paulo: SBF, 1996. p. 347- 356.

TERRAZZAN, E. A.; PIMENTEL, N. L.; SILVA, L. L.; AMORIM, M. A. L. Estudo das analogias utilizadas em coleções didáticas de Biologia, Física e Química. Enseñanza de las Ciencias, Número extra, 1-6, 2005.

TERRAZZAN, E. A. Analogias y metaforas en la ensenanza de las ciencias naturales. In: CONGRESO INTERNACIONAL DE FORMACION DE PROFESORES, I, 1996, Santa Fé, Argentina. Anais...

TERRAZZAN, E. A.; FELTRIN, C. C. Analogias em aulas de física: exemplos em eletricidade e óptica. In: ENCONTRO DE PESQUISA EM ENSINO DE FÍSICA, VII, 2000, Florianópolis. Anais... Santa Catarina, 2000. v. 1.

TERRAZZAN, E. A.; PIMENTEL, N. L.; SILVA, L. L.; AMORIM, M. A. L. Estudo das analogias utilizadas em Coleções Didáticas de Biologia, Física e Química. Enseñanza de las Ciencias, v. Extra, p. 1-12, 2005. 
TERRAZZAN, E. A.; SILVEIRA, L. M.; SCHMIDT, I. P. Dificuldades de professores de física de ensino médio na utilização de analogias para o estudo de circuitos elétricos. In: ENCONTRO NACIONAL DE PESQUISA EM ENSINO DE CIÊNCIAS, I, 1997, Águas de Lindóia. Anais... São Paulo: ABRAPEC, 1997.

TERRAZZAN, E. A.; FERRAZ, D. F.; GIRALDI, P. M.; AMORIM, M. A. L.; PIMENTEL, N. L.; DIAS, D. S.; SILVA, L. L.; POZZER, L. L. Analogias no ensino de Ciências: Resultados e perspectivas. In: SEMINÁRIO DE PESQUISA EM EDUCAÇÃO REGIÃO SUL, III, 2000, Porto Alegre. Anais...

TERRAZZAN, E. A. Potencial didático dos textos de divulgação científica: um exemplo em física. In: CONGRESSO DE LEITURA DO BRASIL, 12, 2000, Campinas. Textos de palestras e sessões temáticas: III Encontro de Linguagens e Ensino da Ciência. Campinas: UNICAMP, 2000 .

TERRAZZAN, E. A.; AMORIM, M. A. L.; PIMENTEL, N. L.; FELTRIN, C.; DIAS, D. S.; FERRAZ, D. F.; SILVA, L. L.; POZZER, L. L.; GIRALDI, P. M. Analogias no ensino de ciências: resultados e perspectivas. In: SEMINÁRIO DE PESQUISA EM EDUCAÇÃO DA REGIÃO SUL, III, Porto Alegre, 2000. Anais...

TERRAZZAN, E. A.; FOLGEARINI, S. F. G.; FELTRIN, C. C.; SILVEIRA, L. M.; SCHMIDT, I. P. A utilização das analogias em artigos de divulgação científica sobre física moderna. In: SIMPÓSIO NACIONAL DE ENSINO DE FÍSICA, XIII, 1999, Brasília. Anais... Distrito Federal: SBF, 1999.

TERRAZZAN, E. A.; GABANA, M.; LUNARDI, G. Textos de divulgação científica: avaliando uma estratégia didática para o ensino de médio. In: SIMPÓSIO NACIONAL DE ENSINO DE FÍSICA, XV, 2003, Curitiba. Anais... Paraná: SBF, 2003.

TERRAZZAN, E. A.; SANTOS, C. L. Utilizando analogias para ensinar Física: uma experiência no Ensino Médio. In: SIMPÓSIO NACIONAL DE ENSINO DE FÍSICA, XVI, 2005, Rio de Janeiro. Anais... Rio de Janeiro: SBF, 2003.

TERRAZZAN, E. A.; SCHMIDT, I. P.; SILVEIRA, L. M. Analogies in physics teaching: a study on their use in classrooms and textbooks. In: INTERNATIONAL CONFERENCE OF E.S.E.R.A, I, European Science Education Research Association, 1997, Roma. Anais...

TRIVIÑOS, A. N. S. Introdução à pesquisa em Ciências Sociais: a pesquisa qualitativa em Educação. São Paulo: Editora Atlas, 1987.

VALENTE, L.; BARCELLOS, M.; ZANETIC, J. Entrevista com Einstein. In: SIMPÓSIO NACIONAL DE ENSINO DE FÍSICA, XVII, 2007, São Luís. Anais... Maranhão: SBF, 2007. 
VIENNOT, L. Le raisonnement spontanne en dynamic elementaire. 1977. Tese (Doutorado) - Universidade Paris VII, Paris.

VIERNE, S. Ligações tempestuosas: a ciência e a literatura. In: CORBOZ, A. et. al. Ciência e imaginário. Brasília: Editora UnB, 1994.

VYGOTSKY, L.S. Pensamento e Linguagem. São Paulo: Editora Martins Fontes, 2008.

WATANABE, G.; GURGEL, I. A imaginação como processo de criação na arte e na física: uma discussão sobre a dualidade no entendimento. In: SIMPÓSIO NACIONAL DE ENSINO DE FÍSICA, XIX, 2011, Manaus. Anais... Amazonas: SBF, 2011.

WELlEK, R.; WARREN, A. Teoria da literatura. Tradução: José Palla e Carmo. Lisboa: Publicações Europa-América, 1962.

WONG, E. D. Understanding the generative capacity of analogies as a tool for explanation. Journal of Research in Science Teaching, v. 30, n. 10, p. 1259-1272, 1993.

ZAMBON, L.; TERRAZZAN, E. A. A utilização de analogias na prática docente e professores da área de ensino de Ciências Naturais. In: ENCONTRO NACIONAL DE DIDÁTICA E PRÁTICA DE ENSINO, XV, 2010, Belo Horizonte. Anais... p.1-12.

ZAMBON; L. B; TERRAZZAN, E. A. Analogias produzidas por alunos do ensino médio em aulas de física. Revista Brasileira de Ensino de Física, v. 35, n. 1, p. 1505, 2013.

ZANETIC, J. Ciência e Arte: aproximações no ensino de Física e na formação de professores de Física. In: SIMPÓSIO NACIONAL DE ENSINO DE FÍSICA, XVII, 2007, São Luís. Anais... Maranhão: SBF, 2007.

ZANETIC, J. Física ainda é cultura! In: MARTINS, A. F. P. (Org.) Física ainda é cultura? São Paulo: Editora Livraria da Física p. 176-189, 2009.

ZANETIC, J. Física e arte: uma ponte entre duas culturas. In: ENCONTRO NACIONAL DE PESQUISA EM EDUCAÇÃO EM CIÊNCIAS, IV, 8, 2002, Águas de Lindóia. Anais... São Paulo: ABRAPEC, 2002. 1 CD-ROM.

ZANETIC, J. Física e Arte: uma ponte entre duas culturas. Pro-Posições, Campinas, v. 17, n. 1, p. 39-58, 2006.

ZANETIC, J. Física e Cultura. Ciência e Cultura, São Paulo, v. 57, n. 3, 2005.

ZANETIC, J. Física e literatura: uma possível integração no ensino. Cadernos Cedes: Ensino da Ciência, Leitura e Literatura, v. 41, p. 46-61, 1997. 
ZANETIC, J. Física e literatura: uma possível integração no ensino. In: ENCONTRO DE PESQUISA EM ENSINO DE FÍSICA, V 1996, Águas de Lindóia. Anais... São Paulo: SBF, 1996, p. 27-33.

ZANETIC, J. Física Também é Cultura. 1989. Tese (Doutorado em Educação) - Faculdade de Educação, USP.

ZANETIC, J. Literatura e cultura científica. In: ALMEIDA, M. J. P. M. de; SILVA, H. C. da (Orgs.). Linguagens, leituras e ensino da ciência. Campinas: Mercado de Letras, 1998. p. 1136.

ZANOTELLO, M.; ALMEIDA, M. J. P. M. Produção de sentidos e possibilidades de mediação na física do ensino médio: leitura de um livro sobre Isaac Newton. Revista Brasileira de Ensino de Física, v. 29, 3, p. 437-446, 2007.

ZILBERMAN, R. Teoria da Literatura I. Curitiba: Editora IESDE, 2012. 